Document downloaded from:

http://hdl.handle.net/10251/145534

This paper must be cited as:

Moraes, J.; Tashima, M.; Melges, J.; Akasaki, J.; Monzó Balbuena, JM.; Borrachero Rosado, MV.; Soriano Martinez, L.... (06-2). Optimum use of sugar cane straw ash (SCSA) in alkaliactivated binders based on blast furnace slag (BFS). Journal of Materials in Civil Engineering. 30(6):1-12. https://doi.org/10.1061/(ASCE)MT.1943-5533.0002261

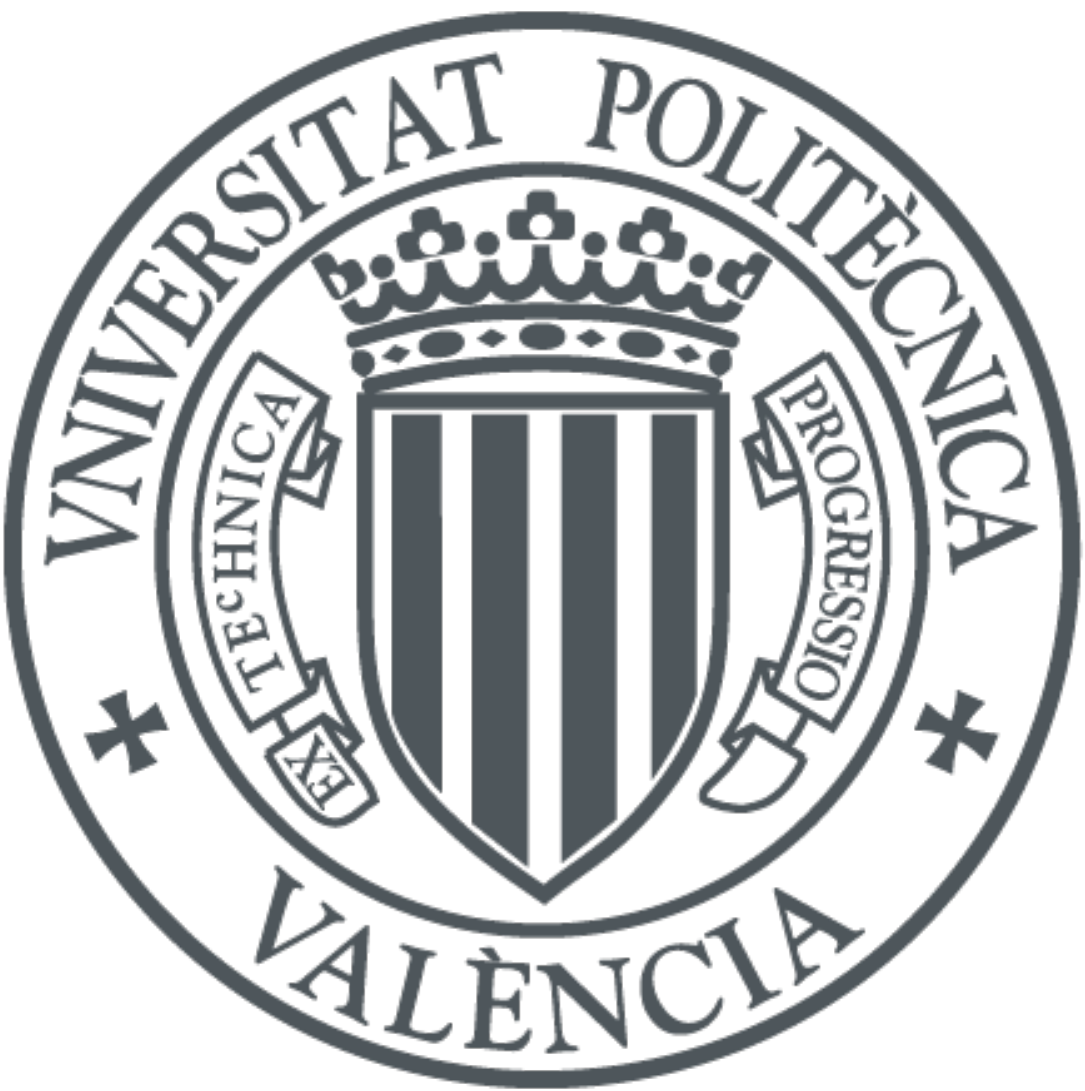

The final publication is available at

https://doi.org/10.1061/(ASCE)MT.1943-5533.0002261

Copyright American Society of Civil Engineers

Additional Information 


\section{Optimum Use of Sugar Cane Straw Ash in Alkali-Activated Binders Based on Blast Furnace Slag}

João Claudio Bassan de Moraes, P.G. ${ }^{1}$; Mauro Mitsuuchi Tashima, Ph.D. ${ }^{2}$; José Luiz Pinheiro Melges, Ph.D. ${ }^{3}$; Jorge Luís Akasaki, Ph.D. ${ }^{4}$; José Monzó, Ph.D. ${ }^{5}$; Maria Victoria Borrachero, Ph.D. ${ }^{6}$; Lourdes Soriano, Ph.D. ${ }^{7}$; and Jordi Payá, Ph.D. ${ }^{8}$

\footnotetext{
${ }^{1}$ Grupo de Pesquisa MAC - Materiais Alternativos de Construção. Universidade Estadual Paulista (UNESP), Faculdade de Engenharia de Ilha Solteira, Campus de Ilha Solteira. Alameda Bahia, 550, 15385-000, Ilha olteira/SP. ${ }^{2}$ Grupo de Pesquisa MAC - Materiais Alternativos de Construção. Universidade Estadual Paulista (UNESP), Faculdade de Engenharia de Ilha Solteira, Campus de Ilha Solteira. Alameda Bahia, 550, 15385-000, Ilha Solteira/SP (corresponding author). maumitta@ hotmail.com tel: +55 1837431217

${ }^{3}$ Grupo de Pesquisa MAC - Materiais Alternativos de Construção. Universidade Estadual Paulista (UNESP), Faculdade de Engenharia de Ilha Solteira, Campus de Ilha Solteira. Alameda Bahia, 550, 15385-000, Ilha Solteira/SP.

${ }^{4}$ Grupo de Pesquisa MAC - Materiais Alternativos de Construção. Universidade Estadual Paulista (UNESP), Faculdade de Engenharia de Ilha Solteira, Campus de Ilha Solteira. Alameda Bahia, 550, 15385-000, Ilha Solteira/SP.

${ }^{5}$ GIQUIMA Group - Grupo de Investigación en Química de los Materiales de Construcción, ICITECH - Instituto de Ciencia y Tecnología del Hormigón, Universitat Politècnica de València, UPV. Camino de Vera, s/n, 4N, 46022, Valencia, Valencia, Spain.

${ }^{6}$ GIQUIMA Group - Grupo de Investigación en Química de los Materiales de Construcción, ICITECH - Instituto de Ciencia y Tecnología del Hormigón, Universitat Politècnica de València, UPV. Camino de Vera, s/n, 4N, 46022, Valencia, Valencia, Spain.

${ }^{7}$ GIQUIMA Group - Grupo de Investigación en Química de los Materiales de Construcción, ICITECH - Instituto de Ciencia y Tecnología del Hormigón, Universitat Politècnica de València, UPV. Camino de Vera, s/n, 4N, 46022, Valencia, Valencia, Spain.

${ }^{8}$ GIQUIMA Group - Grupo de Investigación en Química de los Materiales de Construcción, ICITECH - Instituto de Ciencia y Tecnología del Hormigón, Universitat Politècnica de València, UPV. Camino de Vera, s/n, 4N, 46022, Valencia, Valencia, Spain.
}

\section{ABSTRACT}

Alkali-activated binders $(\mathrm{AAB})$ are a material obtained from the combination of a solid precursor and an alkaline activating solution. In this study, one solid precursor utilised was blast furnace slag (BFS) and the other was an agro waste: sugar cane straw ash (SCSA). Sodium hydroxide was used for preparing activating solutions. In order to reach the potential reactivity of the SCSA, a study varying the $\mathrm{BFS} / \mathrm{SCSA}$ mass ratio and $\mathrm{H}_{2} \mathrm{O} / \mathrm{Na}_{2} \mathrm{O}$ molar ratio was carried out. The $\mathrm{BFS} / \mathrm{SCSA}$ 
ratio varied from $100 / 0$ to $70 / 30$, and $\mathrm{H}_{2} \mathrm{O} / \mathrm{Na}_{2} \mathrm{O}$ was studied in the range of $11.1-18.5$. To fulfil this objective, specimens were assessed by their compressive strength of mortars and microstructural studies of pastes (X-ray diffraction, XRD; thermogravimetric analysis, TGA; Fourier transform infrared spectroscopy, FTIR; field emission scanning electron microscopy, FESEM) in the curing time range of 3-90 days at $25^{\circ} \mathrm{C}$. Results from these tests showed that the best BFS/SCSA and $\mathrm{H}_{2} \mathrm{O} / \mathrm{Na}_{2} \mathrm{O}$ ratios were $70 / 30$ and 18.5 , respectively. This study revealed an interesting valorisation of the SCSA as a complementary precursor in BFS-based alkali-activated binders due to the improvement of mechanical properties and the reduction in the consumption of $\mathrm{BFS}$ in $\mathrm{AAB}$.

KEYWORDS: agro waste, optimum replacement, microstructural studies, compressive strength

\section{INTRODUCTION}

The recent concerns in the last decades about the reduction of three worldwide problems, which are high $\mathrm{CO}_{2}$ (greenhouse gas) emissions, the use of non-renewable raw materials and energy consumption, have increased the investigation of new sustainable and environmentally friendly materials (Shi 2011; Madlool 2013; Turner 2013; Usón 2013; Zhang 2014). In building construction, these concerns are related to the current widespread use of Portland cement, which is one of the most used materials in the world (Shen 2014). In this binder production process, a total energy of $3000 \mathrm{MJ}$ is spent per ton of clinker, and the raw materials (mainly limestone and clay) involved in this manufacturing procedure are from non-renewable sources (Usón 2013). As concerns the greenhouse gas emissions from cement production, it is responsible for emitting 5- 
7\% of the total world emissions (Turner 2014). Therefore, in order to reduce the consumption of Portland cement, a new type of environmentally friendly material that are being widely studied is presented as an interesting option: alkali-activated binders (AAB) (Provis 2015). These binders are obtained when a highly concentrated alkaline solution is mixed with a solid precursor (usually an amorphous aluminosilicate), and this combination generates binding gels with mechanical properties and durability similar to or even better than Portland cement mixtures (Provis 2014; Pacheco-Torgal 2015). The environmentally friendly characteristics of AAB come from the reduced $\mathrm{CO}_{2}$ emissions and energy consumption (Duxson 2007; van Deventer 2010; Turner 2013), as well as the use of by-products from important industries as solid precursors in their mixtures, such as blast-furnace slag (BFS) and fly ash (FA) (Provis 2014; Pacheco-Torgal 2015). One of the most studied precursors in AAB is blast-furnace slag (Shi 2006). This precursor can be easily activated by the addition of an alkali hydroxide solution. Regarding the activating solution, it has an important role in the development of the mechanical properties of the AAB (Wang 1995; Tashima 2013; Aydin 2014; Ozer 2015). The most utilised reagent is sodium hydroxide $(\mathrm{NaOH})$ (Provis 2014; Pacheco-Torgal 2015). In the activation of BFS with $\mathrm{NaOH}$, the main reaction compound is $\mathrm{C}(\mathrm{N})-\mathrm{A}-\mathrm{S}-\mathrm{H}$ gel. The $\mathrm{Na}^{+}$sourced from the hydroxide is important to balance the extra negative charge from the $\mathrm{AlO}_{4}{ }^{5-}$ when it replaces the $\mathrm{SiO}_{4}{ }^{4-}$ in the tetrahedrally coordinated form, and it helps to form a more polymerised gel (Provis 2014; Pacheco-Torgal 2015). Therefore, the $\mathrm{Na}^{+}$concentration has an important role in the final gel structure. Another important issue is the $\mathrm{OH}^{-}$concentration sourced from the hydroxide: previous studies showed that the use of sodium hydroxide is beneficial to accelerate the reaction process of BFS (Song 1999; Song 2000). However, at very high values of pH (> 13.0), which are 
obtained by using more than $1 \mathrm{M}$ of $\mathrm{NaOH}$, the anions (silica and alumina) take an important role in the gel structure development (Fernández-Jiménez 2003).

BFS presents an important environmental impact advantage when compared to Portland cement: the $\mathrm{CO}_{2}$ emissions are up to $85 \%$ less than the conventional one (Özbay 2016). However, the increased use of BFS in the cement industries has resulted in the monetary cost of this binder increasing in the same way (Meyer 2009). Thus, an option that investigators are researching to reduce the use of BFS is through the employment of binary systems. These systems consist in partially replacing the BFS with another mineral admixture in order to maintain or even increase the properties of the newly designed alkali-activated binder. In the recent bibliography, some examples can be found of binders utilised in binary systems with BFS, such as fly ash (Chi 2013), red clay brick waste (Rakhimova 2015) and metakaolin (Borges 2016). An alternative to reduce the cost of the final alkali-activated binders and also to increase even more their environmentally friendly and sustainable characteristics is the use of ashes from biomass wastes as solid precursors. One example of agro waste is sugar cane bagasse ash (SCBA). Previous studies on binary BFS/SCBA systems have shown that is possible to utilise them together with some improvement in the mechanical properties of alkali-activated binders (Castaldelli 2013; Pereira 2015).

In this scenario of using biomass wastes, another residue has been increasing in Brazil in recent years: sugar cane straw. Two main factors explain this increase: the expansion of sugarcane production and the trend to use mechanized harvesting. As concerns the first reason, sugar cane production grew by $166 \%$ since the beginning of this century until 2016 , mainly due to the 
production of ethanol to be used as a car fuel (Moraes 2015a; União da Indústria de Cana-deAçúcar 2016). Regarding the mechanized harvesting factor, it has increased because a protocol signed in Brazil prohibited pre-burning the sugar cane plant in the field - a process that makes it easier to harvest the sugar cane - due to environmental and safety issues (Leal 2013). Therefore, mechanized harvesting has been shown to be a suitable method to pick sugar cane. However, after this procedure, a waste is generated that contains mainly the leaves from the crop: the sugar cane straw. Like sugar cane bagasse, this waste has an interesting calorific value as shown by some authors (Leal 2013; Uzun 2017), and can be used as a biomass to produce energy. Hence, researchers are studying methods to optimise the collection process, and the best burning method for this material to obtain the maximum energy recovery (Lemos 2014; Alves 2015). There is a high probability that this waste will become a trend to obtain energy from the burning process. However, after obtaining energy from the biomass through this procedure, a residue is generated that needs to be valorised: sugar cane straw ash (SCSA). This ash is basically formed by amorphous silica with good pozzolanic reactivity, as shown in a previous study (Moraes 2016a). When the SCSA was assessed as a partial replacement for Portland cement, it could be used up to a $30 \%$ replacement percentage without significant changes in the mechanical properties (Moraes 2015b). The new goal of employing SCSA is to utilise it in combined systems with blast-furnace slag in alkali-activated binders. SCSA is an important source of amorphous $\mathrm{SiO}_{2}$ to the mixture, which means that its presence causes changes in the gel composition of BFS-based AAB. Hence, there are optimum amounts of both sodium hydroxide and SCSA that can be incorporated into the mixture to achieve the best mechanical properties. A previous study of a BFS/SCSA system activated by 8 molar $\mathrm{NaOH}$ solution showed that the ash improved the compressive strength from early ages when compared to the BFS mortars (Moraes 2016b). In 
this study, the best replacements of BFS by SCSA found for 7 and 28 days curing times were 15 and $25 \%$.

This present paper assesses the effect of the $\mathrm{NaOH}$ concentration of the alkaline solution on the activation of a binary BFS/SCSA system in order to achieve the best compressive strength development and calculate the cementing efficiency of SCSA in BFS-based AAB. For this purpose, a set of dosages were prepared in this investigation: the BFS/SCSA proportions assessed were $100 / 0,90 / 10,80 / 20$ and $70 / 30$, while the $\mathrm{H}_{2} \mathrm{O} / \mathrm{Na}_{2} \mathrm{O}$ molar ratios studied were 11.1, 12.3, 13.9, 15.9 and 18.5. This study was carried out on mortars and pastes: the former were assessed by their compressive strength, and the latter were analysed by X-ray diffraction (XRD), Fourier transform infrared spectroscopy (FTIR), thermogravimetric analysis (TGA), and field emission scanning electron microscopy (FESEM).

\section{MATERIALS AND METHODS}

\section{Materials}

The solid precursors utilised in this study were blast-furnace slag (BFS) and sugar cane straw ash (SCSA). BFS was obtained from Ribas do Rio Pardo (Mato Grosso do Sul, Brazil). SCSA was prepared in three steps: straw calcination, following by sieving and, finally, milling the passing ash. Firstly, the burning process of the sugar cane straw was carried out by an autocombustion process (Moraes 2016b). The remaining ash was sieved (0.297 mm, MESH \#50) to remove some unburned particles and impurities. The final step was milling the passing material for 50 minutes. 
The chemical composition obtained from X-ray fluorescence (XRF) of both materials is given in Table 1. It can be seen that the SCSA presents $\mathrm{SiO}_{2}$ as the main compound. Regarding the BFS, the main oxides are $\mathrm{SiO}_{2}, \mathrm{Al}_{2} \mathrm{O}_{3}$ and $\mathrm{CaO}$. The particle sizes of BFS and SCSA are shown through mean $\left(\mathrm{D}_{\text {med }}\right)$ and median $\left(\mathrm{D}_{50}\right)$ diameters: the former material presents values of 21.0 and $13.4 \mu \mathrm{m}$, respectively; whereas these values for the ash are 18.1 and $10.6 \mu \mathrm{m}$. Regarding the activating solution, only sodium hydroxide pellets were utilised $(\mathrm{NaOH}$, solid, purity higher than 99\%), provided by Dinâmica Química. For mortars manufacturing, natural sand was utilised with a specific gravity of $2667 \mathrm{~kg} / \mathrm{m}^{3}$ and fineness modulus of 2.05 and was supplied from Castilho city (Sao Paulo, Brazil).

\section{Design of alkali-activated binders}

The optimum use of SCSA on BFS-based AAB was determined by varying the $\mathrm{Na}^{+}$ concentration in the alkaline solution (represented by the $\mathrm{H}_{2} \mathrm{O} / \mathrm{Na}_{2} \mathrm{O}$ molar ratio) and the proportion of solid precursors (BFS/SCSA mass ratio). The designed $A A B$ presented $\mathrm{H}_{2} \mathrm{O} / \mathrm{Na}_{2} \mathrm{O}$ molar ratio values of $11.1,12.3,13.9,15.9$ and 18.5 , corresponding to $\mathrm{Na}^{+}$concentrations of 10 , 9, 8, 7 and 6 mol. $\mathrm{kg}^{-1}$, respectively (five ratios). For each of these ratio values, the BFS/SCSA proportions assessed were 100/0 (control), 90/10, 80/20 and 70/30 (four proportions). Therefore, the total number of dosages studied was twenty. The nomenclature proposed for these dosages is $\mathrm{x}-\mathrm{y} / \mathrm{z}$, where the " $\mathrm{x}$ " is related to the $\mathrm{H}_{2} \mathrm{O} / \mathrm{Na}_{2} \mathrm{O}$ molar ratios presented previously (for simplicity, "x" values were 11,12,14, 16 and 19), while " $y / z$ " is associated with the BFS/SCSA proportions assessed in this study. With respect to the water/binder (w/b, the binder being the sum of BFS and SCSA) and aggregate/binder (a/b) ratios, they were maintained as constants: the former ratio 
was 0.45 for both pastes and mortars, while the latter proportion was 2.5 for mortars (both ratios by mass).

\section{Tests carried out for pastes and mortars}

For the macrostructural studies, the compressive strength of mortars was measured by an EMIC Universal Machine with a $2000 \mathrm{kN}$ load limit at a loading rate of $0.5 \mathrm{MPa} / \mathrm{s}$. In this test, three cubic mortars of $50 \times 50 \times 50 \mathrm{~mm}^{3}$ were tested to obtain an average of the compressive strength and the standard deviation. In the following microstructural studies, the pastes were evaluated by X-ray diffraction (XRD), Fourier transform infrared spectroscopy (FTIR), thermogravimetric analysis (TGA), field emission scanning electron microscopy (FESEM) and energy-dispersive X-ray spectroscopy (EDS). XRD was performed by a Bruker AXS D8 Advance, with a voltage of $40 \mathrm{kV}$

and current intensity of $20 \mathrm{~mA}$, where the Bragg's angle (20) assessed was in the range of 5-70 with a step of $0.02^{\circ}$ and step time of $2 \mathrm{~s} / \mathrm{step}$. The FTIR equipment utilised was a Bruker Tensor 27 in the wavenumber range of 400 and $4000 \mathrm{~cm}^{-1}$, the scan frequency was $0.25 \mathrm{~s}^{-1}$ and the resolution was $4 \mathrm{~cm}^{-1}$. TGA studies were carried out by a Mettler-Toledo TGA 850 thermobalance, where the specimen was heated in a $70 \mu \mathrm{L}$ alumina crucible in the temperature range of 35-1000 ${ }^{\circ} \mathrm{C}$, with a heating rate of $20^{\circ} \mathrm{C} \cdot \mathrm{min}^{-1}$ in an air atmosphere $\left(75 \mathrm{~mL} \cdot \mathrm{min}^{-1}\right.$ gas flow). Finally, FESEM images and EDS results were taken by a ZEISS Supra 55 in fractured specimens covered with carbon. Micrographs were taken with an extra high tension (EHT) of $2 \mathrm{kV}$, whereas for EDS analysis was $20 \mathrm{kV}$. The working distance (WD) for both cases was 5-8 mm. EDS analysis was obtained by an average of at least five points in different regions of the sample. 
Regarding the testing ages and curing conditions, all the designed mortars were evaluated by their compressive strength after $3,7,28$ and 90 days of curing at $25^{\circ} \mathrm{C}$ and relative humidity (RH) higher than $95 \%$. Related to the pastes samples, selected mixes were assessed after 7, 28 and 90 days of curing in the same conditions of the mortars (curing temperature and $\mathrm{RH}$ ) as for the FTIR and TGA tests. For XRD, FESEM and EDS tests, samples were analysed only after 90 days of curing in the same conditions. The information on these tests and the dosages utilised for each experiment are summarized in Table 2.

\section{RESULTS AND DISCUSSION}

\section{Compressive strength of mortars}

\section{a) Influence of the $\mathrm{H}_{2} \mathrm{O} / \mathrm{Na}_{2} \mathrm{O}$ molar ratio}

The influence of the $\mathrm{H}_{2} \mathrm{O} / \mathrm{Na}_{2} \mathrm{O}$ molar ratio on the compressive strength of mortars is illustrated in Fig. 1. The assessed BFS/SCSA proportions were 100/0 (Fig. 1a), 90/10 (Fig. 1b), 80/20 (Fig. 1c) and 70/30 (Fig. 1d) after 3, 7, 28 and 90 days of curing. It is first observed that the highest $\mathrm{H}_{2} \mathrm{O} / \mathrm{Na}_{2} \mathrm{O}$ molar ratio yielded the greatest compressive strength in the analysed curing ages for all proportions of solid precursors. Additionally, for a given BFS/SCSA proportion and curing time, it is noticed that there is a linear relationship between the values of compressive strength and the $\mathrm{H}_{2} \mathrm{O} / \mathrm{Na}_{2} \mathrm{O}$ ratio. Therefore, a fitting straight line is proposed for each curing time of a given BFS/SCSA relation. The slope values of the proposed straight line were also obtained. Therefore, the straight lines generated will be discussed by their slope values (Table 3). The 
slope value indicates the impact on the compressive strength development of the $\mathrm{H}_{2} \mathrm{O} / \mathrm{Na}_{2} \mathrm{O}$ molar ratios: a high slope value means that the compressive strength is more affected by variation of $\mathrm{H}_{2} \mathrm{O} / \mathrm{Na}_{2} \mathrm{O}$ relations.

On one hand, the presence of SCSA up to $20 \%$ in the mixture did not cause significant changes: the slope values of BFS/SCSA proportions of $90 / 10$ and 80/20 are similar to the control. In other words, the effect of the sodium content on the compressive strength of mixtures with SCSA percentages of $0-20 \%$ was similar. On the other hand, the proportion of 70/30 showed the highest slope values, which means that there is more influence of the activator concentration for this proportion of SCSA in the mixture. It was observed in previous studies with sodium silicate that the $\mathrm{Na}^{+}$concentration influenced more significantly the compressive strength development than for a system without sodium silicate (Wang 1995; Aydın 2012; Aydın 2014). This behaviour was also observed when the SCSA was utilised, which was suggested by a higher slope values for BFS/SCSA proportion of 70/30. From these results, it can be concluded that the best $\mathrm{H}_{2} \mathrm{O} / \mathrm{Na}_{2} \mathrm{O}$ molar ratio was 18.5 , independently of the BFS/SCSA proportion assessed. 


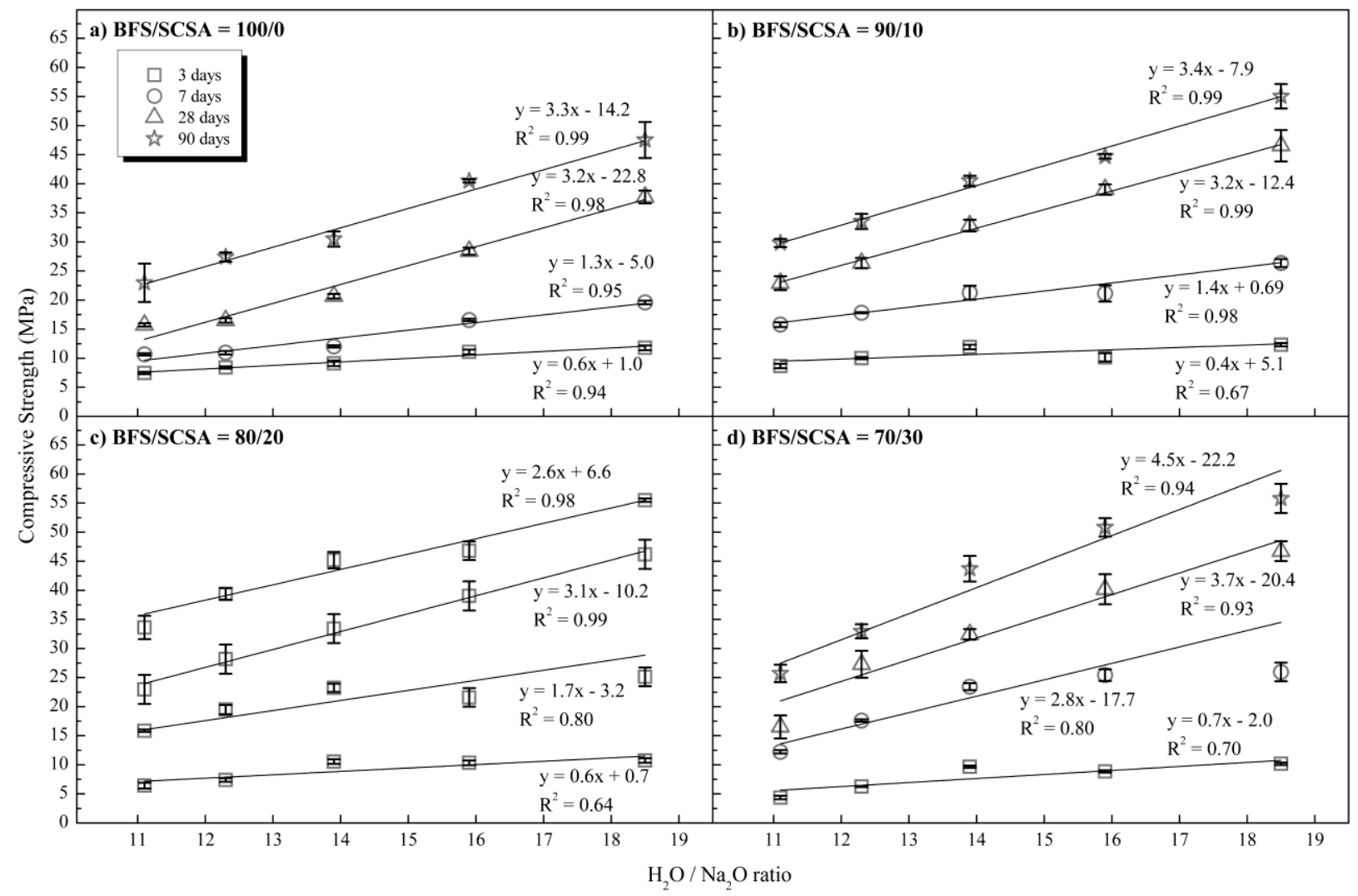

Fig. 1. Influence of the $\mathrm{H}_{2} \mathrm{O} / \mathrm{Na}_{2} \mathrm{O}$ ratio by line adjustment on BFS/SCSA proportions of a) 100/0, b) 90/10, c) 80/20 and d) 70/30 after 3, 7, 28 and 90 days of curing at $25^{\circ} \mathrm{C}$.

\section{b) Influence of the SCSA replacement percentage}

The relative influence of the SCSA replacement in the mixtures was described by a $\sigma_{\mathrm{SCSA}}$ factor. This factor represents the relative contribution of the SCSA to the compressive strength of AAB mortars. The calculated factor is obtained by the compressive strength of a SCSA-mortar with a given $\mathrm{H}_{2} \mathrm{O} / \mathrm{Na}_{2} \mathrm{O}$ molar ratio $\left(\mathrm{R}_{\mathrm{x}-\mathrm{y} / \mathrm{z}}\right)$ from which the compressive strength of its respective control $\left(\mathrm{R}_{\mathrm{x}-100 / 0}\right)$ is subtracted, corrected by the relative percentage of BFS in the mixture, which is the ratio of BFS mass ( $\left.\mathrm{m}_{\mathrm{BFS}}\right)$ over the total binder mass $\left(\mathrm{m}_{\mathrm{BFS}}+\mathrm{m}_{\mathrm{SCSA}}\right)$. The $\sigma_{\mathrm{SCSA}}$ factor is calculated from Equation 1 as follows: 


$$
\sigma_{S C S A}(\%)=\frac{R_{x-y / z}-R_{x-100 / 0}\left(\frac{m_{B F S}}{m_{B F S}+m_{S C S A}}\right)}{R_{x-y / z}} * 100
$$

The results of the $\sigma_{S C S A}$ factor are shown in Fig. 2 for the following curing times: 3 (Fig. 2a), 7

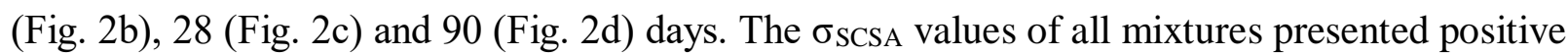
values (except for 11-70/30 after 3 days of curing), showing that the SCSA contributed positively in all mixture proportions and all curing ages.

It is also observed that with the increase of SCSA in the mixture, the contribution of the ash in the compressive strength increases also: the SCSA percentage of 30\% reached the highest values. In addition, a high contribution at the curing times of 7-90 days was noticed, where SCSA is responsible for $30-65 \%$ of the developed compressive strength. The highest SCSA contribution was observed for the $\mathrm{H}_{2} \mathrm{O} / \mathrm{Na}_{2} \mathrm{O}$ molar ratio of 13.9: this $\mathrm{Na}^{+}$concentration probably activates the $\mathrm{SiO}_{4}{ }^{4-}$ anions from the ash better (the best $\mathrm{SiO}_{2} / \mathrm{Na}_{2} \mathrm{O}$ ratio). This $\mathrm{H}_{2} \mathrm{O} / \mathrm{Na}_{2} \mathrm{O}$ molar ratio does not mean that this is the best compressive strength in terms of absolute values, but the ratio of 13.9 is the one that most favours the use of SCSA in this case. In general terms, these values show that SCSA makes an important contribution to the development of the compressive strength of the mortars for all $\mathrm{H}_{2} \mathrm{O} / \mathrm{Na}_{2} \mathrm{O}$ molar ratios. 

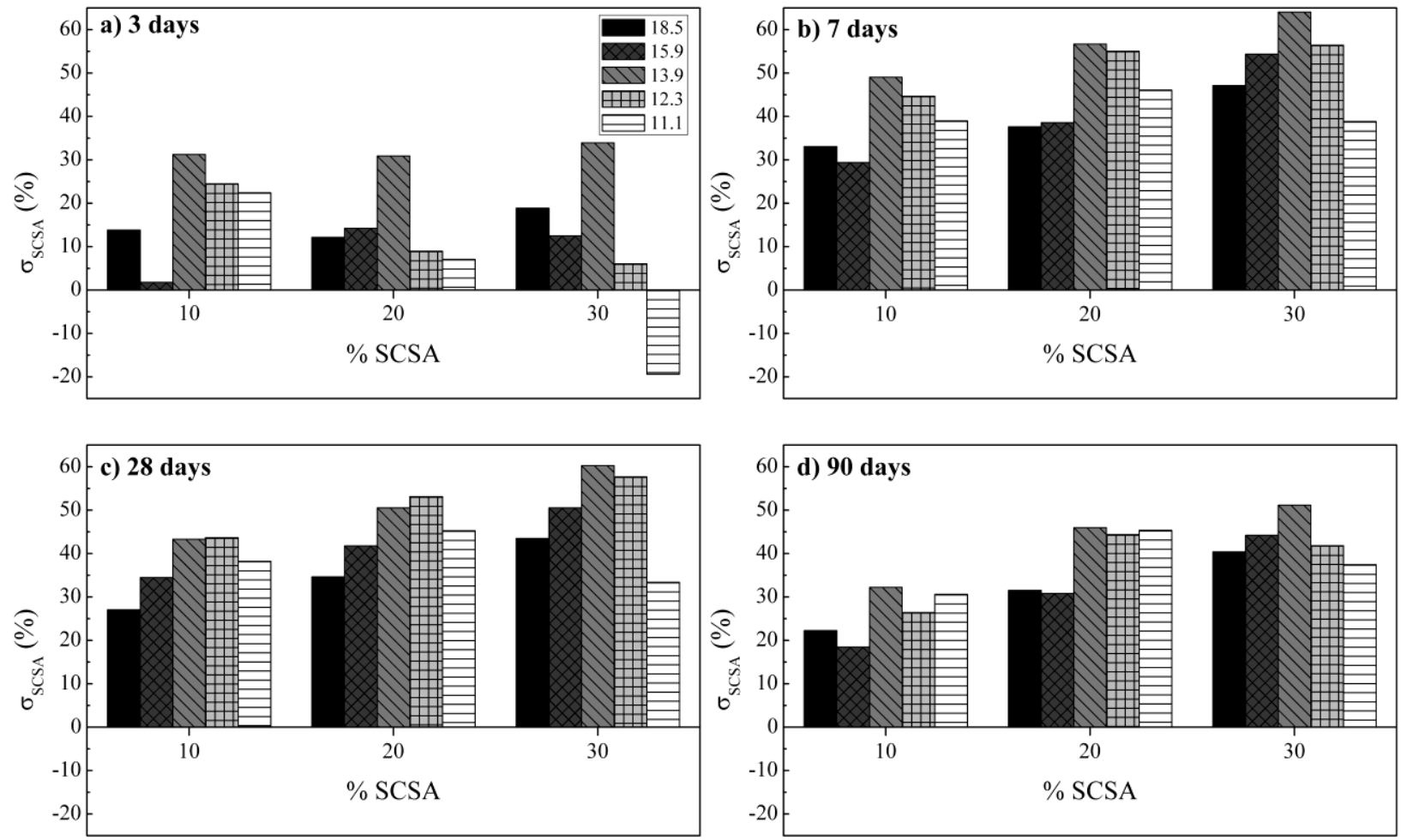

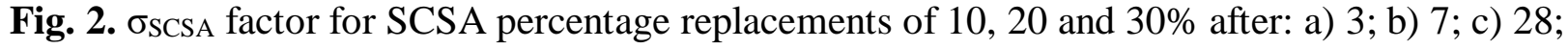
and d) 90 days of curing at $25^{\circ} \mathrm{C}$.

\section{c) Optimum BFS/SCSA proportion}

Studies to determine the optimum BFS/SCSA proportion through compressive strength results are illustrated in Fig. 3. This figure shows plots of compressive strength versus the SCSA percentage in the mixture (\% SCSA) for $\mathrm{H}_{2} \mathrm{O} / \mathrm{Na}_{2} \mathrm{O}$ molar ratios of 11.1 (Fig. 3a), 13.9 (Fig. 3b) and 18.5 (Fig. 3c) after 3, 7, 28 and 90 days of curing. A fitting cubic function is proposed in order to obtain mathematically the optimum percentage of SCSA (highest compressive strength value) for each curing time. The best BFS/SCSA proportion was represented by points in the fitting curve with the respective optimum percentage of SCSA written below. 
The proposed fitting cubic function showed that, after 3 days of curing, it is already interesting to use SCSA in alkali-activated binders, since the best SCSA percentage was in the range of 7-9\%. The $\mathrm{SiO}_{4}{ }^{4-}$ groups from SCSA work as a silica source from sodium silicate (Moraes 2016), explaining the higher strength of SCSA mortars with respect to the control. Additionally, the filler effect of SCSA particles in the matrix may be also taken into account in the first curing days. Over the curing time, the optimum BFS/SCSA proportion moved to a higher SCSA percentage. This can be seen through 7, 28 and 90 days of curing, where the optimum percentage of SCSA was in the intervals of 10-30\%, 15-30\% and 19-30\%, respectively. Another fact noted was that, with the increase of $\mathrm{Na}^{+}$molarity (decrease in the $\mathrm{H}_{2} \mathrm{O} / \mathrm{Na}_{2} \mathrm{O}$ molar ratio), the optimum percentage of SCSA moves to lower values: $\mathrm{H}_{2} \mathrm{O} / \mathrm{Na}_{2} \mathrm{O}$ ratios of $18.5,13.9$ and 11.1 had the optimum percentage at 30, 23 and 19\%, respectively, after 90 days of curing. For low $\mathrm{H}_{2} \mathrm{O} / \mathrm{Na}_{2} \mathrm{O}$ ratios, increasing the amount of SCSA over the optimum value reduces the compressive strength due to problems in products formation. Previous studies concluded that a high presence of sodium combined with a great amount of amorphous silica (in this case, sourced from the high percentages of SCSA) favours crystalline structures or soft gels that reduce the compressive strength (Schilling 1994; Jambunathan 2013; Yusuf 2014; Rashad 2016). This problem is not observed for lower amounts of sodium, since the $\mathrm{H}_{2} \mathrm{O} / \mathrm{Na}_{2} \mathrm{O}$ molar ratio of 18.5 with $30 \%$ of SCSA presented the highest compressive strength. However, percentages of SCSA over $30 \%$ with low $\mathrm{Na}^{+}$molarity present hardening problems (Moraes 2017). It can be concluded that it is more interesting to use percentages of SCSA in the range of $20-30 \%$ until the curing time assessed (90 days). 

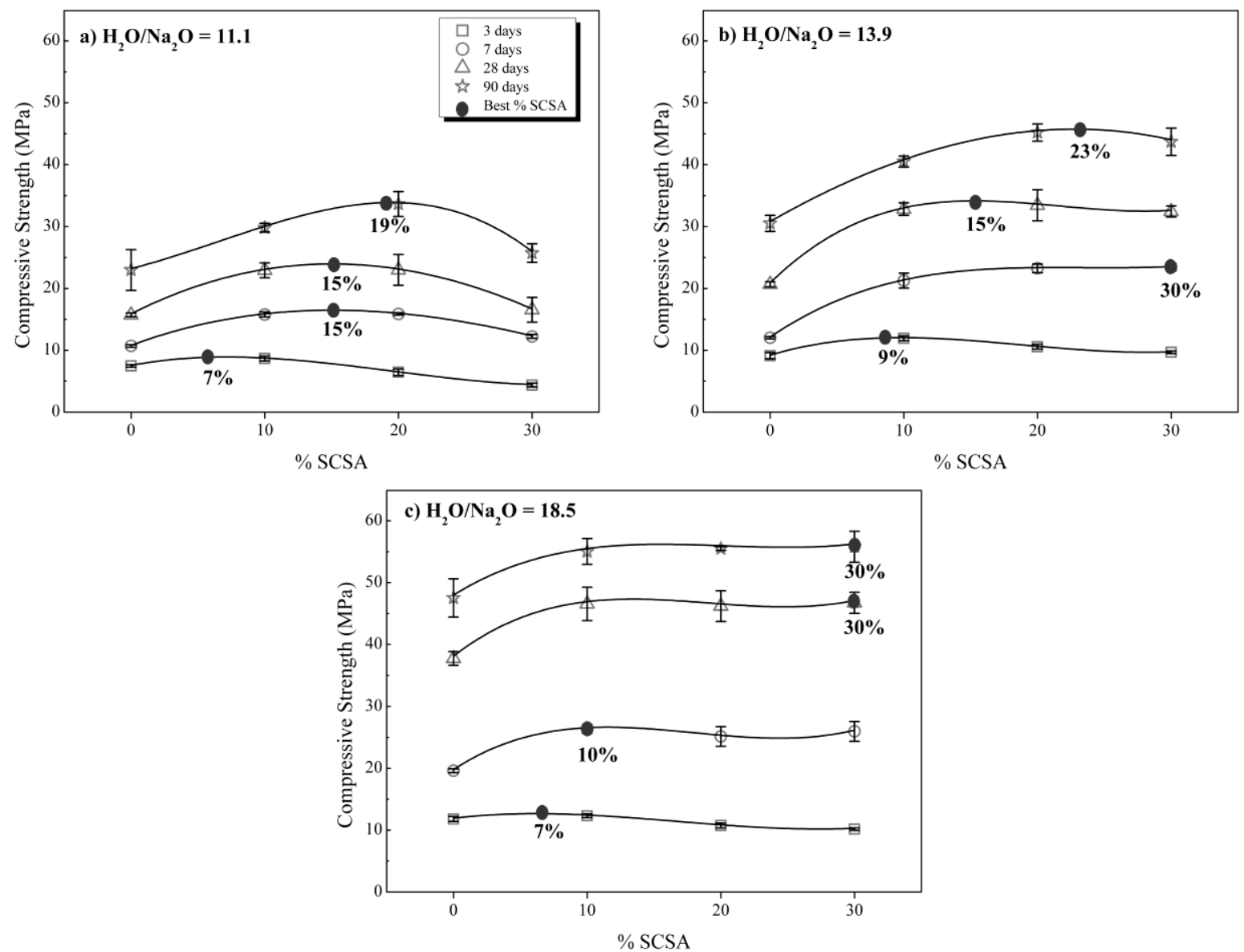

Fig. 3. Best BFS/SCSA proportion for the $\mathrm{H}_{2} \mathrm{O} / \mathrm{Na}_{2} \mathrm{O}$ ratios of: a) 11.1 ; b) 13.9 ; and c) 18.5 after 3, 7, 28 and 90 days of curing at $25^{\circ} \mathrm{C}$.

\section{d) Optimum use of SCSA in BFS-based alkali-activated binders}

Fig. 4 shows a non-linear fitting surface of compressive strength in a graph of the SCSA percentage in the mixture (\% SCSA) versus the $\mathrm{H}_{2} \mathrm{O} / \mathrm{Na}_{2} \mathrm{O}$ molar ratio considering the results after 90 days of curing. The optimum percentage of SCSA for each $\mathrm{H}_{2} \mathrm{O} / \mathrm{Na}_{2} \mathrm{O}$ molar ratio was calculated by the fitting cubic function in the last item, and it is represented in this figure by points connected by a solid curve. It is observed that the highest compressive strength is obtained 
with increase of the SCSA and $\mathrm{H}_{2} \mathrm{O} / \mathrm{Na}_{2} \mathrm{O}$ molar ratio. Therefore, the optimum use of SCSA in BFS-based alkali-activated binders is obtained with a BFS/SCSA proportion of 70/30 and $\mathrm{H}_{2} \mathrm{O} / \mathrm{Na}_{2} \mathrm{O}$ molar ratio of 18.5 .

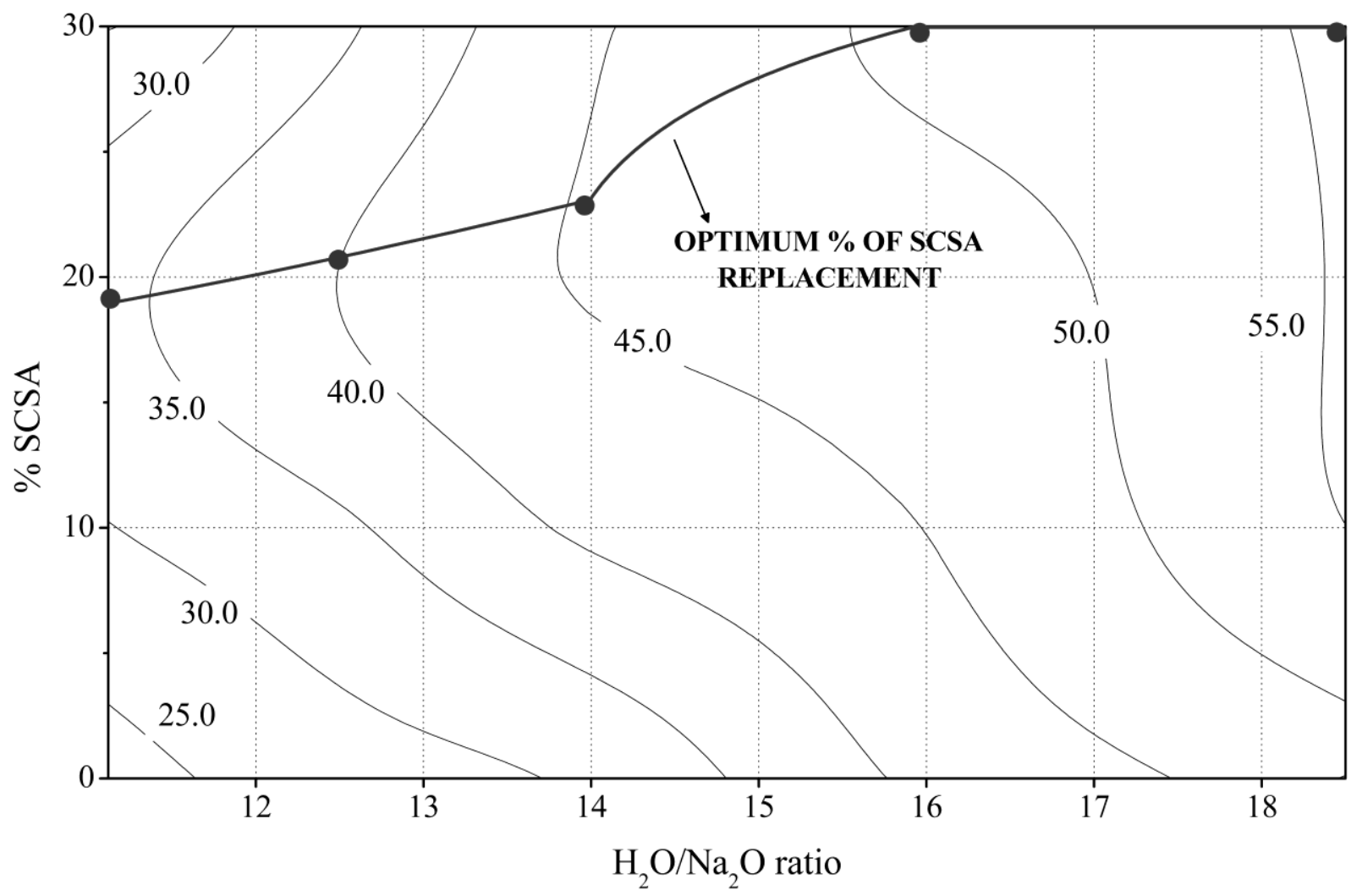

Fig. 4. Non-linear fitting surface of compressive strength values considering all the results after 90 days of curing. Points linked by a solid curve represent the optimum percentage of SCSA in the mixture.

\section{Microstructural studies}

\section{X-ray diffraction (XRD)}


X-ray diffractions of both raw materials (BFS and SCSA) and the alkali-activated pastes are shown in Fig. 5 for pastes with 90 days of curing. Fig. 5a presents the patterns of the pastes 19100/0 (control) and 19-80/20 in order to investigate the influence of the SCSA on the BFS-based alkali-activated binders. Firstly, as concerns the raw materials, the BFS pattern showed a baseline deviation in the Bragg's angle range of $19-37^{\circ}$ related to the amorphous phase of this precursor. On the other hand, the only crystalline phase determined was quartz (PDF Card \#331161). Turning to the SCSA pattern, it presented a baseline deviation from the amorphous phase in the Bragg's angle range of $20-35^{\circ}$ shown in the amplification of the diffractogram. Crystalline phases detected in the SCSA were quartz and calcite (PDF Card \#050586). Regarding the diffractogram of the pastes, the addition of SCSA to the mixture did not alter the formation of crystalline phases in this case. The crystalline phases determined in both pastes were hydrotalcite (PDF Card \#140191), which is common in the alkaline activation of BFS (Pereira 2015; Moraes 2016b; Abdalqader 2016), katoite (PDF Card \#380368) and faujasite (PDF Card \#391380). The only difference observed was the presence of quartz, but this comes from the SCSA composition and it was not formed during the reaction process of the alkali-activated binders. The amorphous phase behaviour of the pastes also did not show any difference: their diffractograms presented the same baseline deviation in the interval of $2 \theta=20-40^{\circ}$. This shift in the baseline deviation interval from the raw materials ( $2 \theta$ in the range of $19-37^{\circ}$ and $20-35^{\circ}$ for BFS and SCSA, respectively) in the paste ( $2 \theta$ in the range of $20-40^{\circ}$ ) was also observed in previous studies (Pereira 2015; Moraes 2016b; Shearer 2016). The authors attributed this behaviour to the formation of cementing gels. Another indication on the formation of reaction products is the broad peak centred at $29.17^{\circ}$ from the semi-crystalline C-S-H, which was present in both pastes. 
Fig. 5 b illustrates the patterns of the $20 \%$ SCSA-containing pastes $19-80 / 20,14-80 / 20$ and 11 $80 / 20$ in order to assess the influence of the activator concentration on the pastes. The results showed that the alkaline solution concentration influenced the formation of some crystalline phases in the specimens. As can be observed, the higher the presence of $\mathrm{Na}^{+}$, the stronger the crystalline peaks are in the diffractogram. The stronger peak from the semi-crystalline C-S-H (placed at $2 \theta$ equal to $29.17^{\circ}$ ) can be related to the generation of a more crystalline gel structure, i.e., it possibly means the formation of a less polymerised structure that can explain the lower compressive strength with increase of the $\mathrm{Na}^{+}$concentration (Schilling 1994; Jambunathan 2013; Yusuf 2014; Rashad 2016). In addition, the paste with the lowest $\mathrm{H}_{2} \mathrm{O} / \mathrm{Na}_{2} \mathrm{O}$ molar ratio presented the formation of a zeolite type: hydrosodalite (PDF Card \#100401). Previous studies also concluded that a higher concentration of the activator induces the formation of this zeolite (Hanjitsuwan 2014).
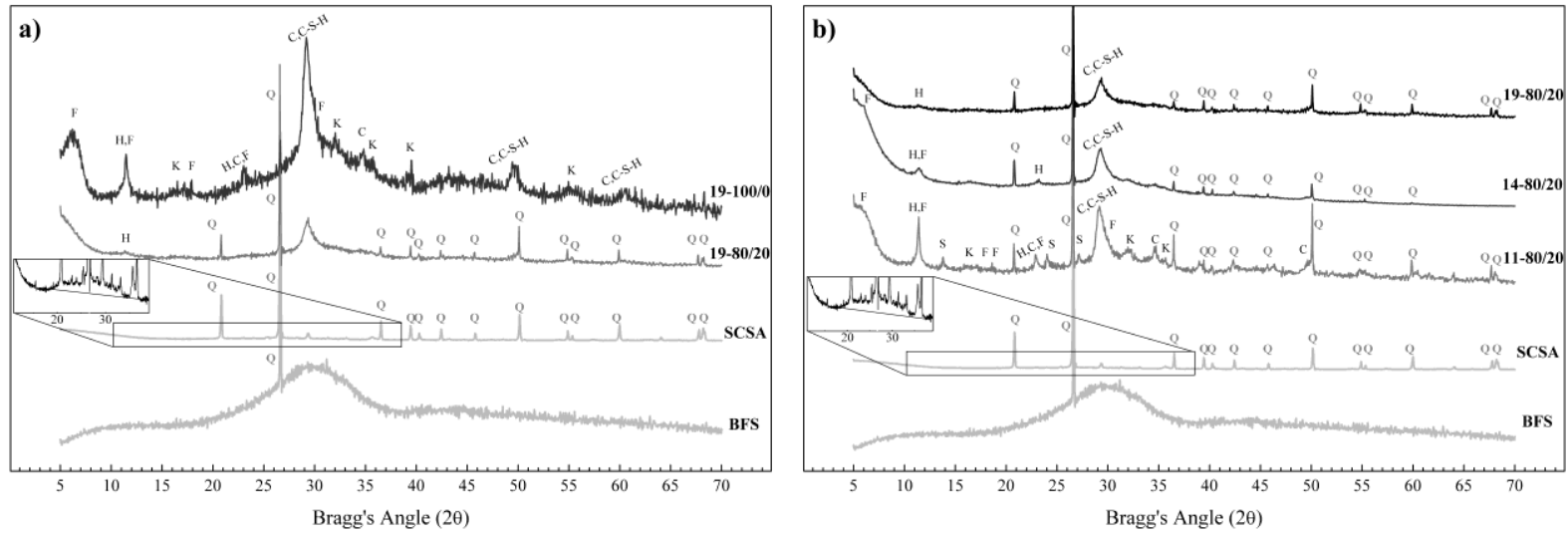

Fig. 5. X-ray diffraction patterns of the raw material and pastes after 90 days of curing: a) BFS and SCSA (raw materials), 19-100/00 and 19-80/20 (pastes); b) BFS and SCSA (raw materials), 19-80/20, 14-80/20 and 11-80/20 (pastes). Key: Q: quartz; C-S-H: semi-crystalline C-S-H; H: hydrotalcite; K: katoite; F: faujasite; C: calcite; S: hydrosodalite. 


\section{Fourier transform infrared spectroscopy (FTIR)}

Fig. 6 shows the FTIR spectra of the raw materials (BFS, SCSA and BFS/SCSA before mixing with the alkaline solution) and pastes cured after 7, 28 and 90 days. In these spectra, the main band was detected within the wavenumber interval of 850 to $1200 \mathrm{~cm}^{-1}$ among the range of 400$4000 \mathrm{~cm}^{-1}$ that was obtained in the test. That wavenumber range is related to bond vibrations of amorphous Si-O-T ( $\mathrm{T}$ being $\mathrm{Si}$ or $\mathrm{Al})$. The position of the band within that interval is associated with the chemical composition of the raw material and, in the case of pastes, it is related to the structure and composition of the formed products (Ismail 2014). Therefore, the FTIR discussion will be focused on variations or differences observed in band positions among the studied spectra. On one hand, the first difference in band positions was observed between both raw materials. The SCSA spectrum presented more absorption at higher wavenumber values than the BFS one (around 1050 and $900 \mathrm{~cm}^{-1}$, respectively). This behaviour is caused by the content of calcium as one of the most abundant elements in the chemical composition of BFS. In the case of the BFS/SCSA blend spectrum, it was observed that the broadness of the main band is the sum of the infrared absorptions of both BFS and SCSA. On the other hand, variation between the raw materials and pastes was also observed: the band position of the pastes shifted when compared to those from the raw materials. The strong absorption of SCSA and BFS was in the wavenumbers of 1050 and $900 \mathrm{~cm}^{-1}$, respectively, whereas for the pastes it was around $950 \mathrm{~cm}^{-1}$. In addition, it was noticed that the BFS/SCSA blend presented a broader band than the pastes. This is explained by the dissolution of the Si-O-T links from the raw materials, followed by the formation of alkali-activated gels (Shearer 2016; Ismail 2014; Salih 2015; Ravikumar 2012). 
Fig. 6a, Fig. 6b and Fig. 6c illustrate the FTIR spectra of the 19-100/0, 19-90/10, 19-80/20 and 19-70/30 pastes (same $\mathrm{H}_{2} \mathrm{O} / \mathrm{Na}_{2} \mathrm{O}$ ratio and four different BFS/SCSA proportions). The aim is to study the SCSA's influence on the alkali-activated binders based on BFS. In these spectra of pastes, the absence of the strongest energy absorption from SCSA (around $1050 \mathrm{~cm}^{-1}$ ) shows that the ash reacted with the BFS and formed binding gels. In general terms, the presence of SCSA up to $30 \%$ of percentage replacement did not significantly alter the spectra with respect to the control. It is observed that the SCSA-pastes presented a slightly higher wavenumber value of the strongest peak than the control. This can be attributed to the formation of a gel with higher $\mathrm{Si}$ content and a more polymerised structure (Shearer 2016; Ravikumar 2015; Zhang 2012; Li 2017). This can be explained by the fact that gels with more Si can incorporate more alkalis in their structure, forming a more linked network (Ravikumar 2015). This gel development is related to the better mechanical response from the SCSA-mortars in compressive strength tests.

Regarding the study of the influence of the alkaline activator, Fig. 6d, Fig. 6e and Fig. $6 \mathrm{f}$ represent the FTIR spectra of $19-80 / 20,14-80 / 20$ and $11-80 / 20$ pastes (three different $\mathrm{H}_{2} \mathrm{O} / \mathrm{Na}_{2} \mathrm{O}$ ratios and the same BFS/SCSA proportion). Once again, minor changes are observed among the three spectra, showing that this technique does not offer, in this case, enough information in terms of changes in the nature of the gel. It is only observed that the increase in the $\mathrm{H}_{2} \mathrm{O} / \mathrm{Na}_{2} \mathrm{O}$ molar ratio of pastes resulted in shifting the wavenumber of the centred peak to higher values. This means that the lowering $\mathrm{Na}^{+}$concentration in the mixture formed a denser structure, explaining the highest compressive strength obtained from the mortars with a low concentration of sodium: in a previous study, it was observed that the increase in the $\mathrm{Na} / \mathrm{Ca}$ ratio in the mixture caused a poor densification of the gel (Bakharev 1999). 

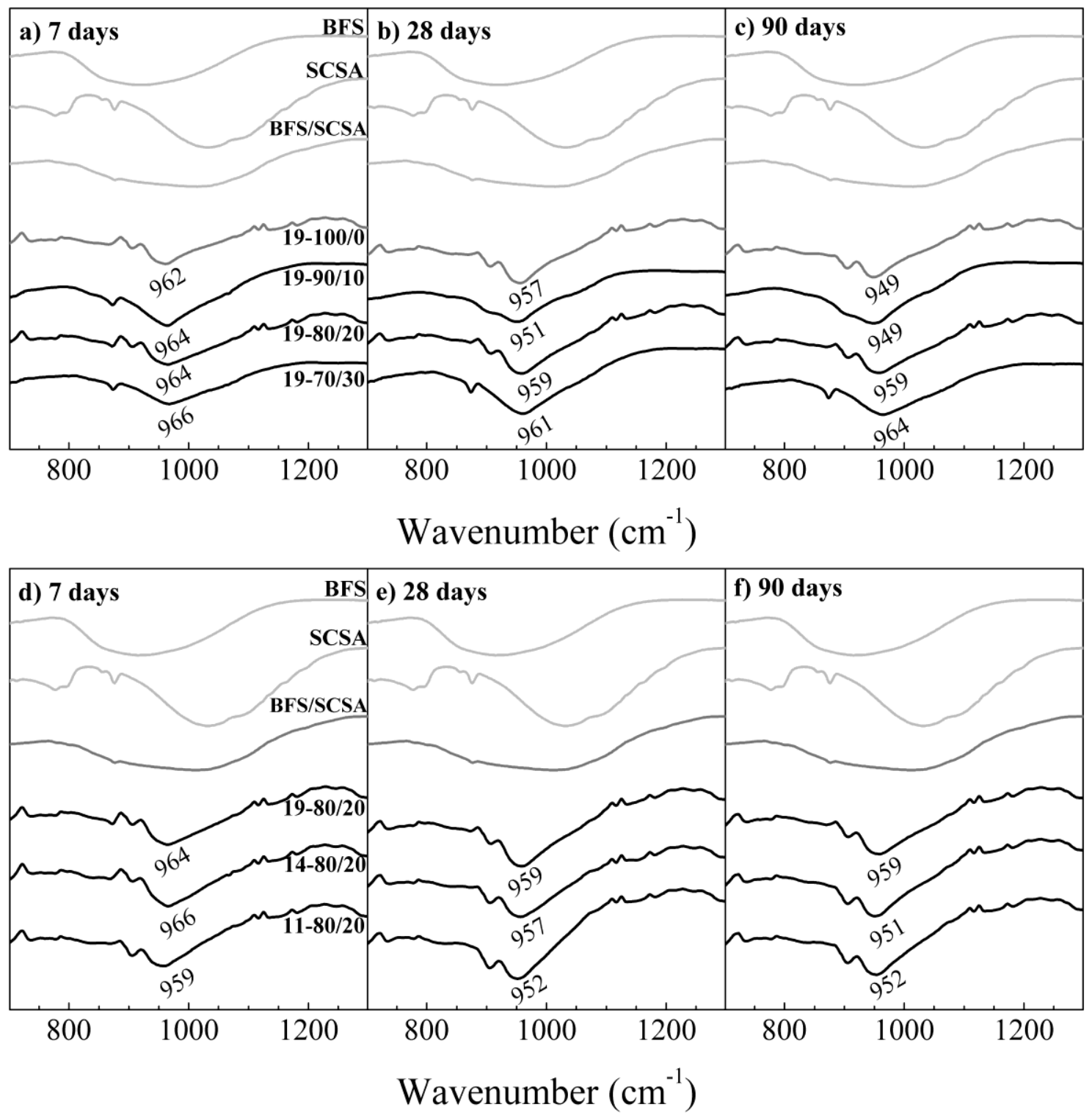

Fig. 6. FTIR spectra of the raw materials (BFS and SCSA) and pastes cured for: a and d) 7 days; b and e) 28 days; and c and f) 90 days at $25^{\circ} \mathrm{C}$. Study on the effect of SCSA content (see a, b and c graphs). Study on the effect of the sodium hydroxide concentration (see d, e and f graphs).

\section{Thermogravimetric analysis (TGA)}


The TGA results are described by both mass losses in Table 4 and DTG curves in Fig. 7 of the pastes after 7, 28 and 90 days of curing. Table 4 is divided into two sections: the SCSA influence and activator concentration effect. The peaks determined in these curves were in the range of $130-160,200-210,380-420$ and $750-800^{\circ} \mathrm{C}$. The first peak $\left(130-160^{\circ} \mathrm{C}\right)$ is related to the dehydration of the C-S-H or C(N)-A-S-H gels from the alkaline activation of BFS, while the second peak (200-220 ${ }^{\circ} \mathrm{C}$ ) is related to C-A-S-H products (Pereira 2015; Moraes 2016b; Myers 2013). The third peak, placed at $380-420^{\circ} \mathrm{C}$, is due to the dehydration of the hydrotalcite that was detected in the XRD analysis (Jin 2015). Finally, the last peak detected is attributed to the decomposition of $\mathrm{CaCO}_{3}$ (Bernal 2013). The most important information about mass loss in these results comes from the analysis in the decomposition range of $100-250^{\circ} \mathrm{C}$ and the total mass loss.

Fig. 7a, Fig. 7b and Fig. 7c show the DTG curves of the study of the influence of the SCSA for the following pastes 19-100/0, 19-90/10, 19-80/20 and 19-70/30 after 7 (Fig. 7a), 28 (Fig. 7b) and 90 (Fig. 7c) days of curing. After 7 days of curing, the mass losses from the SCSA pastes were slightly higher than the control one, as observed in Table 4 . This means that, at an early age, the role of SCSA is important in the formation of gel. Another fact observed was that the centred peak of the decomposition of C-S-H/C(N)-A-S-H gels (in the range of $130-160^{\circ} \mathrm{C}$ ) of the SCSA-pastes 19-80/20 and 19-70/30 are positioned at higher values than the 19-100/0 and 19-90/10 ones. This possibly reveals the formation of products with strongly bonded water for those pastes, explaining the improved compressive strength at this age (Ismail 2014). In the 28day curing time, the SCSA-pastes had their mass loss increased compared to the control one, suggesting a continuity in the hydration process. Related to the DTG curves, it can be noticed 
that the peak from the C-A-S-H hydration (in the range of $200-220^{\circ} \mathrm{C}$ ) disappeared in the SCSA-containing pastes. This can be explained by the formation of $\mathrm{C}(\mathrm{N})-\mathrm{A}-\mathrm{S}-\mathrm{H}$ gels by the cross-linking among the tobermorite chains of the gel structure (more polymerised gel) (Myers 2013). Probably, the dissolved silica from SCSA contributed to 3D polymerisation and a higher compressive strength was achieved. Another fact observed is that the centred peak from the C-SH/C(N)-A-S-H dehydration shifted to higher temperatures for all analysed pastes. Finally, after 90 days of curing, the control paste showed an increase in the mass loss, while the loss values of the SCSA-pastes were reduced. This result is in contrast with the increase in the compressive strength values in the curing interval of 28-90 days. It can be explained by the improvement in the densification and polymerisation of the gel, where the condensation of $\mathrm{OH}$ groups releases $\mathrm{H}_{2} \mathrm{O}$ molecules (Haha 2011). This process means that the dehydration mass loss from the gels is lowered, explaining the increase in the compressive strength of the mortars.

Fig. 7d, Fig. 7e and Fig. 7f illustrate the DTG curves to assess the activator concentration effect after 7 (Fig. 7d), 28 (Fig. 7e) and 90 (Fig. 7f) days of curing for the following pastes: 19-80/10, $14-80 / 20$ and 11-80/20. In the first curing time analysed (7 days), the increase in the $\mathrm{Na}^{+}$ concentration caused an increase in the mass loss of the pastes. However, this fact did not follow the compressive strength behaviour (Table 3), since the mortars with higher $\mathrm{H}_{2} \mathrm{O} / \mathrm{Na}_{2} \mathrm{O}$ molar ratio presented the best strength values. This behaviour can be attributed to zeolite formation in the mixtures with the highest sodium content from early ages, because the dehydration of this crystalline structure occurs in the same temperature range as the gels (Puertas 2003; Bernal 2011; Gencel 2013). After 28 days of curing, the three pastes presented similar mass loss values. However, the pastes with lower concentrations of $\mathrm{Na}^{+}$showed a greater increase in the mass loss 
in the interval of 7-28 days of curing: 19-80/20 had a mass loss of $9.83 \%$ at 7 days that rose to $15.83 \%$ (6\% of absolute increase) at 28 days, while the $11-80 / 20$ presented $14.60 \%$ and $15.24 \%$ ( $0.64 \%$ of increase), respectively. This behaviour is similar to those found in compressive strength results, where the $19-80 / 20$ showed more strength development than the $11-80 / 20$ one in the 7-28 days curing time interval. This means that this increase in the mass loss can be related to new gel formation. In the last curing time studied (90 days), both 14-80/20 and 11-80/20 pastes showed no difference from 28 days of curing. On the contrary, the 19-80/20 paste presented a reduction in the total mass loss: this behaviour may be related to the gel polymerisation (Haha 2011).
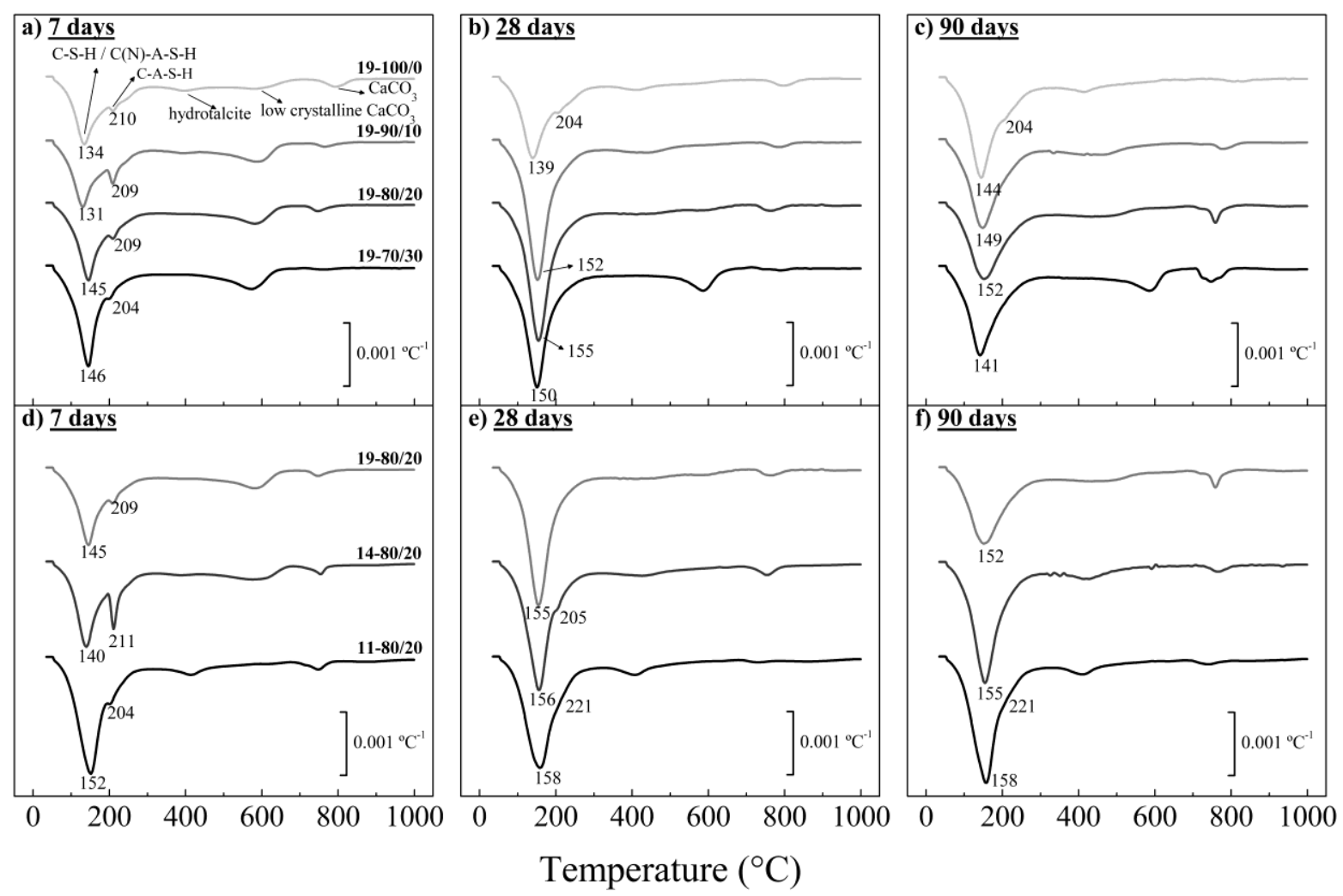

Fig. 7. DTG curves of the pastes: 19-100/0, 19-90/10, 19-80/20 and 19-70/30 cured after a) 7 days, b) 28 days and c) 90 days; and 19-80/20, 14-80/20 and 11-80/20 cured after d) 7 days, e) 28 days and f) 90 days. 


\section{Field emission scanning electron microscopy (FESEM) and Energy-dispersive X-ray spectroscopy (EDS)}

FESEM micrographs of the pastes are shown in Fig. 8 for the samples 19-100/0 (Fig. 8a) and 1980/20 (Fig. 8b) cured after 90 days to study the influence of SCSA. In Fig. 8a, the formation can be observed of a homogeneous gel (gel 1) by activating only the BFS (spot A). At a higher magnification, this observed gel presented a dense surface with some roughness. The composition of gel 1 can be represented by means of the following molar ratios: $\mathrm{Ca} / \mathrm{Si}=0.8 \pm$ $0.1, \mathrm{Na} / \mathrm{Si}=0.3 \pm 0.1, \mathrm{Mg} / \mathrm{Si}=0.3 \pm 0.1$ and $\mathrm{Al} / \mathrm{Si}=0.3 \pm 0.1$. At spot $\mathrm{B}$, a reacting $\mathrm{BFS}$ particle with some superficial gels formation can be seen. In this case, the molar ratios are $\mathrm{Ca} / \mathrm{Si}=1.3$, $\mathrm{Na} / \mathrm{Si}=0.1, \mathrm{Mg} / \mathrm{Si}=0.2$ and $\mathrm{Al} / \mathrm{Si}=0.2$ : it can be seen that the relative content of sodium was significantly lower than that observed for gel 1, suggesting that most of the BFS particles are unreacted. In the case of the paste with SCSA (Fig. 9b), the formation can be seen of two different products at spot C (gel 2) and D (gel 3). Related to the first spot, gel 2 presents a compact and smooth surface with molar ratios of $\mathrm{Ca} / \mathrm{Si}=0.9 \pm 0.1, \mathrm{Na} / \mathrm{Si}=0.3 \pm 0.1, \mathrm{Mg} / \mathrm{Si}=$ $0.1 \pm 0.1$ and $\mathrm{Al} / \mathrm{Si}=0.2 \pm 0.1$. Gel 3 from the second spot shows the formation of some stacked products with molar ratios of $\mathrm{Ca} / \mathrm{Si}=0.9 \pm 0.1, \mathrm{Na} / \mathrm{Si}=1.0 \pm 0.2, \mathrm{Mg} / \mathrm{Si}<0.1$ and $\mathrm{Al} / \mathrm{Si}=0.2 \pm$ 0.1. Besides the difference in the form of both gels, gel 3 presents a higher content of $\mathrm{Na}$ in its composition than gel 2 and the absence of magnesium. Probably, the magnesium was not detected because this gel 3 was developed mainly from the reaction of SCSA (the BFS had 8.2\% of $\mathrm{MgO}$, a significantly higher value than that for SCSA, $1.6 \%$ according to Table 1 ). 
Comparing both pastes, 19-100/0 and 19-80/20, gel 2 from the sample with SCSA presented a denser structure than gel 1 from the control sample. Probably, this gel formation explains the higher compressive strength of the SCSA mortars. In addition, gel 3 (with composition of C,N$\mathrm{S}(\mathrm{A})-\mathrm{H})$ presumably also contributes to enhancing the mechanical development.

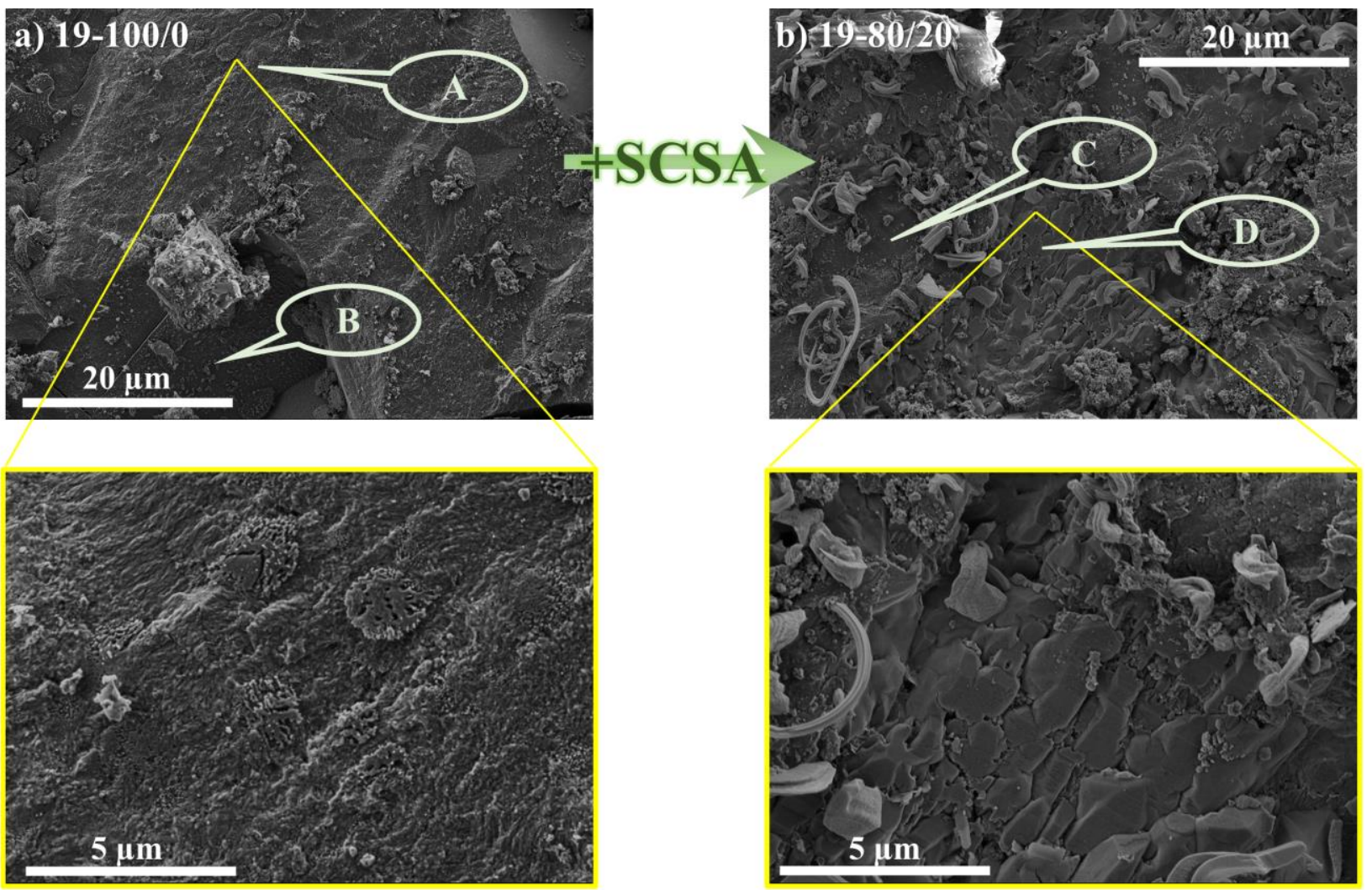

Fig. 8. FESEM micrographs of the pastes: a) 19-100/0; and b) 19-80/20 cured after 90 days.

Fig. 9 illustrates the micrographs of the pastes 19-80/20 (Fig. 9a), 14-80/20 (Fig. 9b) and 1180/20 (Fig. 9c) after 90 days of curing in order to study the influence of the activator on the microstructure of the samples. The 19-80/20 sample was described in the previous paragraph. In the case of the 4-80/20 paste (Fig. 9b), the formation can be seen of several products, gel 4 (spot E) being the most common product observed in the paste. At higher magnification, this product formation is seen to be a group of small particles with low porosity, although it is less compacted 
than gel 2 in the 19-80/20 paste. Finally, the overview of the paste 11-80/20 is shown in Fig. 9c. In general terms, it is noticed that there is the presence of only one gel formation (gel 5). At higher magnification (spot F), this gel shows a very porous and rough surface compared to gels 2 and 4. The chemical composition of gel 5 is represented by molar ratios of $\mathrm{Ca} / \mathrm{Si}=0.9 \pm 0.1$, $\mathrm{Na} / \mathrm{Si}=0.3 \pm 0.1, \mathrm{Mg} / \mathrm{Si}=0.3 \pm 0.1$ and $\mathrm{Al} / \mathrm{Si}=0.2 \pm 0.1$. Comparing the gel formation from the pastes, when the $\mathrm{Na}^{+}$concentration increases, a more porous structure is observed. This behaviour may explain why the mortars with the lowest $\mathrm{Na}^{+}$concentration presented the highest compressive strength.

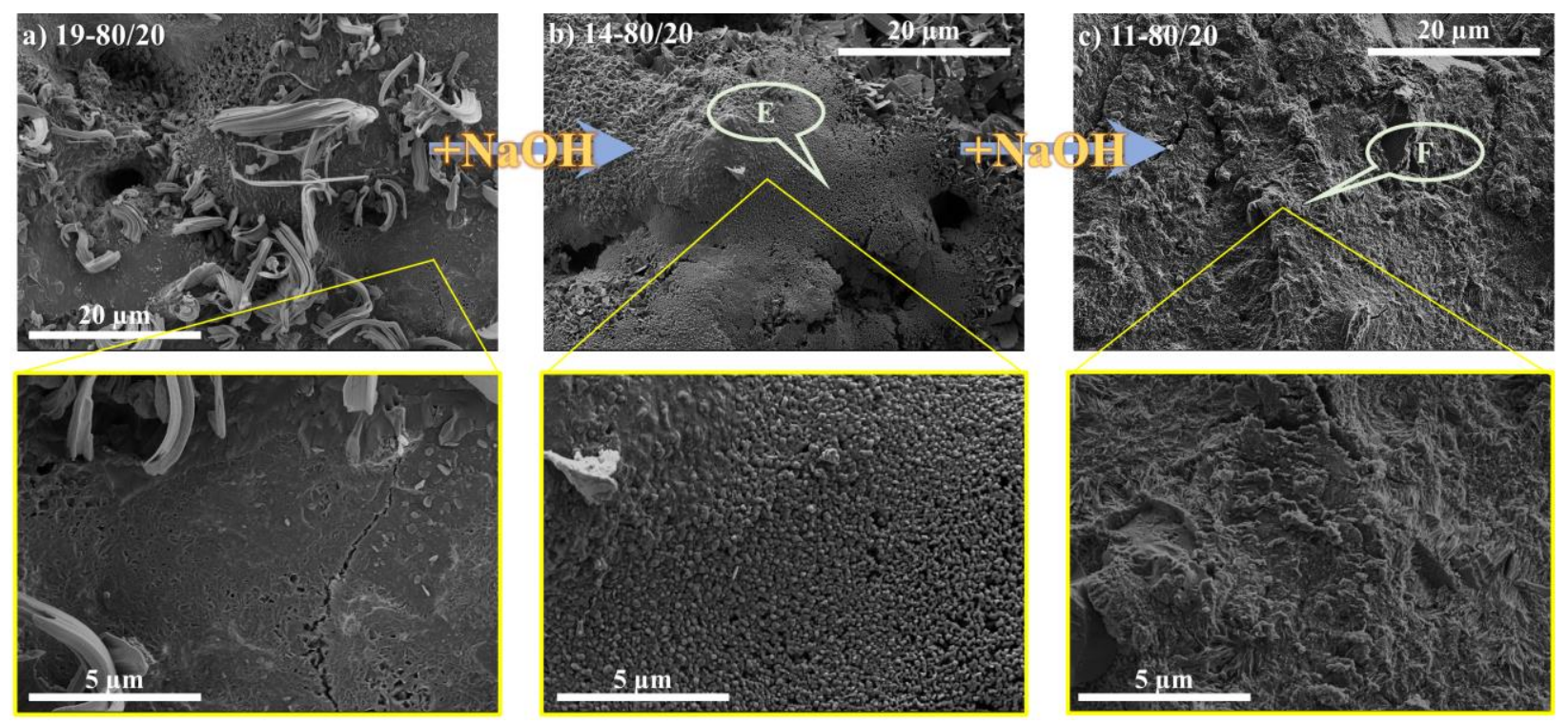

Fig. 9. FESEM micrographs of the pastes: a) 19-80/20; b) 14-80/20; and c) 11-80/20 cured after 90 days.

\section{CONCLUSIONS}

The SCSA was assessed in alkali-activated binders when partially replacing the BFS in the range percentages of $0-30 \%$, where the increase of ash content in the mixture was in intervals of $10 \%$. 
The alkaline solutions were designed with only $\mathrm{NaOH}$, varying the $\mathrm{H}_{2} \mathrm{O} / \mathrm{Na}_{2} \mathrm{O}$ molar ratio in the interval of 11.1-18.5. In 3-90 curing days, the activating solution was found to have an important role in the mechanical development of the AAB. The compressive strength data showed better results for the highest $\mathrm{H}_{2} \mathrm{O} / \mathrm{Na}_{2} \mathrm{O}$ molar ratio (18.5) of activating solution in all BFS/SCSA proportions. The relative influence of SCSA replacement was calculated by means of the $\sigma_{\text {SCSA }}$ factor: BFS/SCSA equal to 70/30 reached the highest mechanical development for activating solutions with a $\mathrm{H}_{2} \mathrm{O} / \mathrm{Na}_{2} \mathrm{O}$ molar ratio higher than 13.9. In general, the compressive strength development of the BFS-based system was enhanced by the presence of SCSA. XRD studies on BFS/SCSA pastes showed that most of the reaction products are amorphous. With the increase of the sodium concentration in the activator, more crystalline phases (faujasite and hydrosodalite) were produced. FTIR spectroscopy studies showed the consumption of amorphous phase from SCSA and confirmed the best development for systems with the highest $\mathrm{H}_{2} \mathrm{O} / \mathrm{Na}_{2} \mathrm{O}$ molar ratio. Thermogravimetric studies showed the effect of SCSA on the hydration process: in the first 28 days of reaction, the combined water in the gels was higher than that found in the BFS control pastes, although at the longer curing time of 90 days, a polymerisation process was observed, which has been related to the strength gain at this curing age. FESEM studies revealed the changes in the nature of the gels formed in the reactions: the gels in SCSA/BFS mixtures contained less magnesium and aluminium and more sodium and calcium than was found for BFS control paste. Additionally, the increase of sodium in activating solution yielded more porous gel, which agrees with the mechanical behaviour. This study revealed an interesting valorisation of the SCSA as an additional precursor in BFS-based alkali-activated binders, in view of the improvement of mechanical properties and the reduction in the consumption of BFS in AAB. 


\section{ACKNOWLEDGEMENTS}

The authors would like to thank CNPq processo n ${ }^{\circ} 401724 / 2013-1$, CNPq processo $^{\circ}$ 140779/2015-0 and the "Ministerio de Educación, Cultura y Deporte" of Spain ("Cooperación Interuniversitaria” program with Brazil PHB-2011-0016-PC). Thanks are also given to the Electron Microscopy Service of the Universitat Politècnica de València.

\section{REFERENCES}

Abdalqader, A. F., Jin, F., and Al-Tabbaa, A. A. (2016). "Development of greener alkaliactivated cement: utilisation of sodium carbonate for activating slag and fly ash mixtures." $J$. Clean. Prod., 113, 66-75.

Alves, M., Ponce, G. H. S. F., Silva, M. A., Ensinas, A. V. (2015). “Surplus electricity production in sugarcane mills using residual bagasse and straw as fuel.” Energy, 91, 751-757. Aydın, S., and Baradan, B. (2012). "Mechanical and microstructural properties of heat cured alkali-activated slag mortars.” Mater. Des., 35, 374-383.

Aydın, S., and Baradan, B. (2014). "Effect of activator type and content on properties of alkaliactivated slag mortars.” J. Compos. Part B, 57, 166-172.

Bakharev, T., Sanjayan, J. G., and Cheng, Y. B. (1999). “Alkali activation of Australian slag cements.” Cem. Concr. Res., 29, 113-120.

Bernal, S. A., Provis, J. L., Walkey, B., Nicolas, R. A., Gehman, J. D., Brice, D. G., Kilcullen, A. R., Duxson, P., and van Deventer, J. S. J. (2013). “Gel nanostructure in alkali-activated 
binders based on slag and fly ash, and effects of accelerated carbonation." Cem. Concr. Res., 53, $127-144$.

Bernal, S. A., Rodríguez, E. D., Gutiérrez, R. B., Gordillo, M., and Provis, J. L. (2011).

"Mechanical and thermal characterisation of geopolymers based on silicate-activated metakaolin/slag blends.” J. Mater. Sci., 46, 5477-5486.

Borges, P. H. R., Banthia, N., Alcamand, H. A., Vascolcelos, W. L., Nunes, E. H. M. (2016). "Performance of blended metakaolin/blastfurnace slag alkali-activated mortars." Cem. Concr. Compos., 71, 42-52.

Brough, A. R., and Atkinson, A. (2002). "Sodium silicate-based, alkali-activated slag mortars. Part I. Strength, hydration and microstructure.” Cem. Concr. Res., 32, 865-879.

Castaldelli, V. N., Akasaki, J. L., Melges, J. L. P., Tashima, M. M., Soriano, L., Borrachero, M. V., Monzó, J., and Payá, J. (2013). "Use of slag/sugar cane bagasse ash (SCBA) blends in the production of alkali-activated materials." Materials, 6, 3108-3127.

Chi, M., and Huang, R. (2013). "Binding mechanism and properties of alkali-activated fly ash/slag mortars." Constr. Build. Mater., 40, 291-298.

Duxson, P., Provis, J. L., Lukey, G. C., and van Deventer, J. S. J. (2007). "The role of inorganic polymer technology in the development of 'green concrete'." Cem. Concr. Res., 37, 1590-1597. Fernández-Jiménez, A., and Puertas, F. (2003). "Effect of activator mix on the hydration and strength behaviour of alkali-activated slag cements." Adv. Cem. Res., 15(3), 129-136.

Gencel, O., Sutcu, M., Erdogmus, E., Koc, V., Cay, V. V., Gok, M. S. (2013). "Properties of bricks with waste ferrochromium slag and zeolite." J. Clean. Prod., 59, 111-119. 
Haha, M. B., Saout, G. L., Winnefeld, F., and Lothenbach, B. (2011). "Influence of activator type on hydration kinetics, hydrate assemblage and microstructural development of alkali activated blast-furnace slags." Cem. Concr. Res., 41, 301-310.

Hanjitsuwan, S., Hunpratub, S., Thongbai, P., Maensiri, S., Sata, V., and Chindaprasirt, P. (2014). "Effects of $\mathrm{NaOH}$ concentrations on physical and electrical properties of high calcium fly ash geopolymer paste.” Cem. Concr. Compos., 45, 9-14.

Ismail, I., Bernal, S. A., Provis, J. L., Nicolas, R. S., Hamdan, S., and van Deventer, J. S. J. (2014). "Modification of phase evolution in alkali-activated blast furnace slag by the incorporation of fly ash." Cem. Concr. Compos. 45, 125-135.

Jambunathan, N., Sanjayan, J. G., Pan, Z., Li, G., Liu, Y., Korayem, A. H., Duan, W. H., Collins, F. (2013). "The role of alumina on performance of alkali-activated slag paste exposed to $50{ }^{\circ} \mathrm{C}$ ". Cem. Concr. Res., 54, 143-150.

Jin, F., Gu, K., and Al-Tabbaa, A. (2015). "Strength and hydration properties of reactive MgOactivated ground granulated blastfurnace slag paste.” Cem. Concr. Res., 57, 8-16.

Juenger, M. C. G., Winnefeld, F., Provis, J. L., and Ideker, J. H. (2011). “Advances in alternative cementitious binders." Cem. Concr. Res., 41, 1232-1243.

Leal, M. R. L. V., Galdos, M. V., Scarpare, F. V., Seabra, J. E. A., Walter, A., and Oliveira, C. O. F. (2013). "Sugarcane straw availability, quality, recovery and energy use: A literature review." Biomass Bioenerg., 53:11-19.

Lemos, S. V., Denadai, M. S., Guerra, S. P. S, Esperancini, M. S. T., Bueno, O. C., and Takitane, I. C. (2014). "Economic efficiency of two baling systems for sugarcane straw." Ind. Crop Prod., $55,97-101$. 
Li, C., Sun, H., and Li, L. (2010). “A review: The comparison between alkali-activated slag ( $\mathrm{Si}+\mathrm{Ca})$ and metakaolin $(\mathrm{Si}+\mathrm{Al})$ cements." Cem. Concr. Res., 40, 1341-1349.

Li, N., Farzadnia, N., Shi, C. (2017). "Microstructural changes in alkali-activated slag mortars induced by accelerated carbonation". Cem. Concr. Res., 100, 214-226.

Madlool, N. A., Saidur, R., Rahim, N. A., and Kamalisarvestani, M. (2013). "An overview of energy savings measures for cement industries.” Renew. Sust. Energ. Rev., 19, 18-29.

Majchrzak-Kuceba, I. (2013). "A simple thermogravimetric method for the evaluation of the degree of fly ash conversion into zeolite material.” J. Porous Mater., 20, 407-415.

Meyer, C. (2009). "The greening of the concrete industry." Cem. Concr. Compos., 31, 601-605. Moraes, B. S., Zaiat, M., and Bonomi, A. (2015a). “Anaerobic digestion of vinasse from sugarcane ethanol production in Brazil: Challenges and perspectives." Renew. Sust. Energ. Rev., 44, 888-903.

Moraes, J. C. B., Akasaki, J. L., Melges, J. L. P., Monzó, J., Borrachero, M. V., Soriano, L., Payá, J., and Tashima, M. M. (2015b). “Assessment of sugar cane straw ash (SCSA) as pozzolanic material in blended Portland cement: Microstructural characterization of pastes and mechanical strength of mortars." Constr. Build. Mater., 94, 670-677.

Moraes, J. C. B., Melges, J. L. P., Akasaki, J. L., Tashima, M. M, Soriano, L., Monzó, J., Borrachero, M. V., and Payá, J. (2016a). "Pozzolanic reactivity studies on a biomass-derived waste from sugar cane production: Sugar cane straw ash (SCSA)." ACS Sust. Chem. Eng., 4, 4273-4279.

Moraes, J. C. B., Tashima, M. M., Akasaki, J. L., Melges, J. L. P., Monzó, J., Borrachero, M. V., Soriano, L., and Payá, J. (2016b). "Increasing the sustainability of alkali-activated binders: the use of sugar cane straw ash (SCSA)." Constr. Build. Mater., 124, 148-154. 
Moraes, J. C. B., Tashima, M. M., Akasaki, J. L., Melges, J. L. P., Monzó, J., Borrachero, M. V., Soriano, L., and Payá, J. (2017). "Effect of sugar cane straw ash (SCSA) as solid precursor and the alkaline activator composition on alkali-activated binders based of blast furnace slag (BFS)." Constr. Build. Mater., 144, 214-224.

Myers, R. P., Bernal, S. A., Nicolas, R. A., and Provis, J. L. (2013). “Generalized structural description of calcium-sodium aluminosilicate hydrate gels: The cross-linked substituted tobermorite model.” Langmuir, 29, 5294-5306.

Özbay, E., Erdemir, M., and Durmus, H. I. (2016). “Utilization and efficiency of ground granulated blast furnace slag on concrete properties - A review." Constr. Build. Mater., 105, 423-434.

Ozer, I., and Soyer-Uzun, S. (2015). "Relations between the structural characteristics and compressive strength in metakaolin based geopolymers with different molar Si/Al ratios.”

Ceram. Int., 41, 10192-10198.

Pacheco-Torgal, F., Labrincha, J. A., Leonelli, C., Palomo, A., and Chindaprasirt, P. (2015). Handbook of Alkali-activated Cements, Mortars and Concretes. $1^{\text {st }}$ ed. Woodhead Publishing and Elsevier, Cambridge, Waltham, Kidlington.

Pereira, A., Akasaki, J. L., Melges, J. L. P, Tashima, M. M., Soriano, L., Borrachero, M. V., Monzó, J., and Payá, J. (2015). "Mechanical and durability properties of alkali-activated mortar based on sugarcane bagasse ash and blast furnace slag." Ceram. Int., 41, 13012-13024.

Provis, J. L., and van Deventer, J. S. J. (2014). Alkali Activated Materials: State-of-the-Art Report. $1^{\text {st }}$ ed. Springer, Dordrecht, Heidelberg, New York, London.

Provis, J. K., Palomo, A., and Shi, C. (2015). "Advances in understanding alkali-activated materials". Cem.Concr. Res., 78(10), 110-125. 
Puertas, F., and Fernández-Jiménez, A. (2003). "Mineralogical and microstructural characterisation of alkali-activated fly ash/slag pastes." Cem.Concr. Compos., 25, 287-292. Puertas, F., Fernández-Jiménez, A., and Blanco-Varela, M. T. (2004). "Pore solution in alkaliactivated slag cement pastes. Relation to the composition and structure of calcium silicate hydrate." Cem. Concr. Res., 34, 139-148.

Rakhimova, N. R., and Rakhimov, R. Z. (2015). “Alkali-activated cements and mortars based on blast furnace slag and red clay brick waste.” Mater. Des., 85, 324-331.

Rashad, A. A., Zeedan, S. R., and Hassan, A. A. (2016). "Influence of the activator concentration of sodium silicate on the thermal properties of alkali-activated slag pastes." Constr. Build. Mater., 102, 811-820.

Ravikumar, D., and Neithalath, N. (2012). "Effects of activator characteristics on the reaction product formation in slag binders activated using alkali silicate powder and $\mathrm{NaOH}$." Cem. Concr. Compos., 34, 809-818.

Salih, M. A., Farzadnia, N., Ali, A. A. A., and Demirboga, R. (2015). "Development of high strength alkali activated binder using palm oil fuel ash and GGBS at ambient temperature." Constr. Build. Mater., 93, 289-300.

Schilling, P. J., Roy, A., Eaton, H. C., Malone, P. G., and Brabston, W. N. (1994). "Microstructure, strength, and reaction products of ground granulated blast-furnace slag activated by highly concentrated $\mathrm{NaOH}$ solution." J. Mater. Res., 9(1), 188-97.

Shi, C., Fernández Jiménez, A., and Palomo, A. (2011). "New cements for the 21st century: The pursuit of an alternative to Portland cement” Cem. Concr. Res., 41(7), 750-763. 
Shi, C., Roy, D. M., and Krivenko P. (2016). Alkali-activated Cements and Concretes. $1^{\text {st }}$ ed., Taylor \& Francis.Shearer, C. R., Provis, J. L., Bernal, S. A., Kurtis, K. E. (2016). “Alkaliactivation potential of biomass-coal co-fired fly ash." Cem. Concr. Res., 73, 62-74.

Shen, L., Gao, T., Zhao, J., Wang, L., Wang, L., Liu, L., Chen, F., and Xue, J. (2014). "Factorylevel measurements on $\mathrm{CO}_{2}$ emission factors of cement production in China." Renew. Sust. Energ. Rev., 34, 337-349.

Song, S., and Jennings, H. M. (1999). "Pore solution chemistry of alkali-activated ground granulated blast-furnace slag." Cem. Concr. Res., 29, 159-170.

Song, S., Sohn, D., Jennings, H. M., and Mason, T. O. (2000). "Hydration of alkali-activated ground granulated blast furnace slag." J. Mater. Sci., 35, 249-257.

Tashima, M. M., Akasaki, J. L., Melges, J. L. P, Soriano, L., Monzó, J., Payá, J., and Borrachero, M. V. (2013). “Alkali activated materials based on fluid catalytic cracking catalyst residue (FCC): Influence of $\mathrm{SiO}_{2} / \mathrm{Na}_{2} \mathrm{O}$ and $\mathrm{H}_{2} \mathrm{O} / \mathrm{FCC}$ ratio on mechanical strength and microstructure." Fuel, 108, 833-839.

Tashima, M. M., Reig, L., Santini Jr, M. A., Moraes, J. C. B., Akasaki, J. L., Payá, J., Borrachero, M. V., and Soriano, L. (2016). "Compressive strength and microstructure of alkaliactivated blast furnace slag/sewage sludge ash (GGBS/SSA) blends cured at room temperature." Waste Biomass Valor., in press.

Turner, L. K., and Collins, F.K. (2013). "Carbon dioxide equivalent $\left(\mathrm{CO}_{2}\right.$-e) emissions: A comparison between geopolymer and OPC cement concrete." Constr. Build. Mater., 43, 125-130. União da Indústria de Cana-de-Açúcar (UNICA). (2016). "Sugarcane production." http://www.unicadata.com.br/index.php?idioma=2 (Oct. 19, 2016) 
Usón, A. A., López-Sabirón, A. M., Ferreira, G., and Sastresa E. L. (2013). “Uses of alternative fuels and raw materials in the cement industry as sustainable waste management options." Renew. Sust. Energ. Rev., 23, 242-260.

Uzun, H., Yıld1z, Z., Goldfarb, J. L., Ceylan, S. (2017). “Improved prediction of higher heating value of biomass using an artificial neural network model based on proximate analysis." Bioresour. Technol., 234, 122-130.

van Deventer, J. S. J., Provis, J. L., Duxson, P., and Brice, D. G. (2010). “Chemical research and climate change as drivers in the commercial adoption of alkali activated materials." Waste Biomass Valor., 1, 145-155

Wang, S. D., Scrivener, J. K. and Prat, P. L. (1994). "Factors affecting the strength of alkaliactivated slag." Cem. Concr. Res., 24(6), 1033-1043.

Yusuf, M. O., Johari, M. A. M., Ahmad, Z. A., and Maslehuddin, M. (2014). "Influence of curing methods and concentration of $\mathrm{NaOH}$ on strength of the synthesized alkaline activated ground slag-ultrafine palm oil fuel ash mortar/concrete.” Constr. Build. Mater., 66, 541-548. Zhang, Z., Provis, J. L., Reid, A., and Wang, H. (2014). “Geopolymer foam concrete: An emerging material for sustainable construction.” Constr. Build. Mater., 56, 113-127.

Zhang, Z., Wang, H., Provis, J. L. (2012). "Quantitative study of the reactivity of fly ash in geopolymerization by FTIR”. J. Sust. Cem. Bas. Mat., 1(4), 154-166. 
Table 1. Chemical composition of the raw materials sugar cane straw ash (SCSA) and blast furnace slag (BFS) in weight percentages

\begin{tabular}{|c|c|c|c|c|c|c|c|c|c|c|}
\hline Solid Precursors & $\mathrm{SiO}_{2}$ & $\mathrm{Al}_{2} \mathrm{O}_{3}$ & $\mathrm{Fe}_{2} \mathrm{O}_{3}$ & $\mathrm{CaO}$ & MgO & $\mathbf{K}_{2} \mathbf{O}$ & $\mathrm{SO}_{3}$ & Cl & Others & LOI \\
\hline SCSA & 58.6 & 9.0 & 8.4 & 4.6 & 1.6 & 5.4 & 1.9 & 0.7 & 3.3 & 6.5 \\
\hline BFS & 42.1 & 11.0 & 1.7 & 33.6 & 8.2 & 1.6 & 0.1 & 0.1 & 1.6 & 0.1 \\
\hline
\end{tabular}


Table 2. Specimen names, mixture designs $\left(\mathrm{H}_{2} \mathrm{O} / \mathrm{Na}_{2} \mathrm{O}\right.$ and BFS/SCSA ratios) and tests performed: compressive strength (Rc), X-ray diffraction (XRD), Fourier transform infrared spectroscopy (FTIR), thermogravimetric analysis (TGA) and field emission scanning electron microscopy (FESEM)

\begin{tabular}{|c|c|c|c|c|c|c|c|}
\hline \multirow{2}{*}{$\begin{array}{l}\text { Specimen } \\
\text { name }\end{array}$} & \multirow{2}{*}{$\mathrm{H}_{2} \mathrm{O} / \mathrm{Na}_{2} \mathrm{O}$} & \multirow{2}{*}{ BFS/SCSA } & \multicolumn{5}{|c|}{ Tests ages (days) } \\
\hline & & & $\mathrm{Rc}$ & XRD & FTIR & TG & FESEM \\
\hline $19-100 / 0$ & \multirow{4}{*}{18.5} & $100 / 0$ & \multirow{4}{*}{$3-7-28-90$} & 90 & $7-28-90$ & $7-28-90$ & 90 \\
\hline $19-90 / 10$ & & $90 / 10$ & & - & $7-28-90$ & $7-28-90$ & - \\
\hline $19-80 / 20$ & & $80 / 20$ & & 90 & $7-28-90$ & $7-28-90$ & 90 \\
\hline $19-70 / 30$ & & $70 / 30$ & & - & $7-28-90$ & $7-28-90$ & - \\
\hline $16-100 / 0$ & \multirow{4}{*}{15.9} & $100 / 0$ & \multirow{4}{*}{$3-7-28-90$} & - & - & - & - \\
\hline $16-90 / 10$ & & $90 / 10$ & & - & - & - & - \\
\hline $16-80 / 20$ & & $80 / 20$ & & - & - & - & - \\
\hline $16-70 / 30$ & & $70 / 30$ & & - & - & - & - \\
\hline $14-100 / 0$ & \multirow{4}{*}{13.9} & $100 / 0$ & \multirow{4}{*}{$3-7-28-90$} & - & - & - & - \\
\hline $14-90 / 10$ & & $90 / 10$ & & - & - & - & - \\
\hline $14-80 / 20$ & & $80 / 20$ & & 90 & $7-28-90$ & $7-28-90$ & 90 \\
\hline $14-70 / 30$ & & $70 / 30$ & & - & - & - & - \\
\hline $12-100 / 0$ & \multirow{4}{*}{12.3} & $100 / 0$ & \multirow{4}{*}{$3-7-28-90$} & - & - & - & - \\
\hline $12-90 / 10$ & & $90 / 10$ & & - & - & - & - \\
\hline $12-80 / 20$ & & $80 / 20$ & & - & - & - & - \\
\hline $12-70 / 30$ & & $70 / 30$ & & - & - & - & - \\
\hline $11-100 / 0$ & \multirow{4}{*}{11.1} & $100 / 0$ & \multirow{4}{*}{$3-7-28-90$} & - & - & - & - \\
\hline $11-90 / 10$ & & $90 / 10$ & & - & - & - & - \\
\hline $11-80 / 20$ & & $80 / 20$ & & 90 & $7-28-90$ & 7-28-90 & 90 \\
\hline $11-70 / 30$ & & $70 / 30$ & & - & - & - & - \\
\hline
\end{tabular}


Table 3. Slope values from the graphic compressive strength versus $\mathrm{H}_{2} \mathrm{O} / \mathrm{Na}_{2} \mathrm{O}$ ratio for the four BFS/SCSA proportions

\begin{tabular}{ccccc}
\hline $\begin{array}{c}\text { BFS/SCSA } \\
\text { proportion }\end{array}$ & 3 days & 7 days & 28 days & 90 days \\
\hline $100 / 0$ & 0.6 & 1.3 & 3.2 & 3.3 \\
$90 / 10$ & 0.4 & 1.4 & 3.2 & 3.2 \\
$80 / 20$ & 0.6 & 1.7 & 3.1 & 2.6 \\
$70 / 30$ & 0.7 & 2.8 & 3.7 & 4.5 \\
\hline
\end{tabular}


Table 4. Mass losses from TGA curves in the $35-250^{\circ} \mathrm{C}$ range $\left(\mathrm{P}_{35-200^{\circ} \mathrm{C}}\right)$ and the total mass loss in $35-1000{ }^{\circ} \mathrm{C}$ range $\left(\mathrm{P}_{\mathrm{T}}\right)$ in pastes cured for 7,28 and 90 days at $25^{\circ} \mathrm{C}$.

\begin{tabular}{|c|c|c|c|c|c|c|c|}
\hline \multirow{2}{*}{ Data analysis } & \multirow{2}{*}{ Specimen } & \multicolumn{3}{|c|}{$\mathrm{P}_{35-250^{\circ} \mathrm{C}}$} & \multicolumn{3}{|c|}{$\mathrm{P}_{\mathrm{T}}$} \\
\hline & & 7 days & 28 days & 90 days & 7 days & 28 days & 90 days \\
\hline \multirow{4}{*}{$\begin{array}{c}\text { SCSA } \\
\text { influence }\end{array}$} & $19-100 / 0$ & 9.26 & 10.94 & 13.31 & 18.21 & 18.59 & 20.84 \\
\hline & $19-90 / 10$ & 9.46 & 16.01 & 12.42 & 20.25 & 23.70 & 21.30 \\
\hline & $19-80 / 20$ & 9.83 & 15.83 & 11.75 & 19.58 & 23.45 & 20.94 \\
\hline & $19-70 / 30$ & 10.94 & 13.84 & 12.11 & 19.89 & 23.29 & 23.82 \\
\hline \multirow{3}{*}{$\begin{array}{c}\text { Activator } \\
\text { concentration } \\
\text { effect } \\
\left(\mathrm{H}_{2} \mathrm{O} / \mathrm{Na}_{2} \mathrm{O}\right. \\
\text { molar ratio } \\
\text { variation) }\end{array}$} & $19-80 / 20$ & 9.83 & 15.83 & 11.75 & 19.58 & 23.45 & 20.94 \\
\hline & $14-80 / 20$ & 11.52 & 15.05 & 15.00 & 22.22 & 23.89 & 23.66 \\
\hline & $11-80 / 20$ & 14.60 & 15.24 & 15.94 & 25.04 & 23.76 & 24.57 \\
\hline
\end{tabular}

